\title{
Summary of Nuclear Regulatory Commission Flood Barrier Testing Strategies Workshop
}

Sai Zhang, Zhegang Ma, Curtis L Smith

April 2020

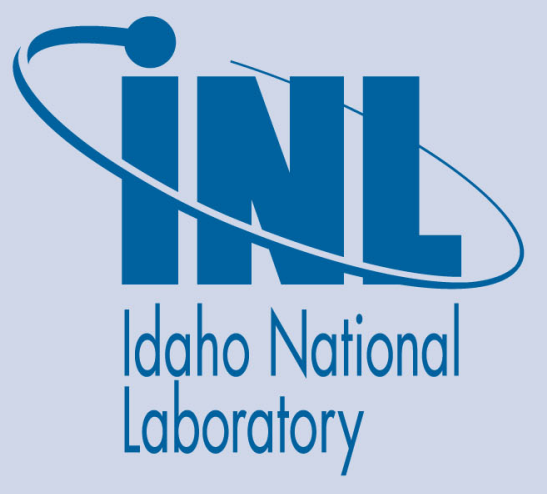

The INL is a U.S. Department of Energy National Laboratory operated by Battelle Energy Alliance 


\section{Summary of Nuclear Regulatory Commission Flood Barrier Testing Strategies Workshop}

Sai Zhang, Zhegang Ma, Curtis L Smith

April 2020

Idaho National Laboratory Idaho Falls, Idaho 83415

http://www.inl.gov

Prepared for the U.S. Department of Energy Office of Nuclear Energy Under DOE Idaho Operations Office

Contract DE-AC07-05ID14517 


\section{Summary of Nuclear Regulatory Commission Flood Barrier Testing Strategies Workshop}

Sai Zhang

Zhegang Ma

Curtis Smith

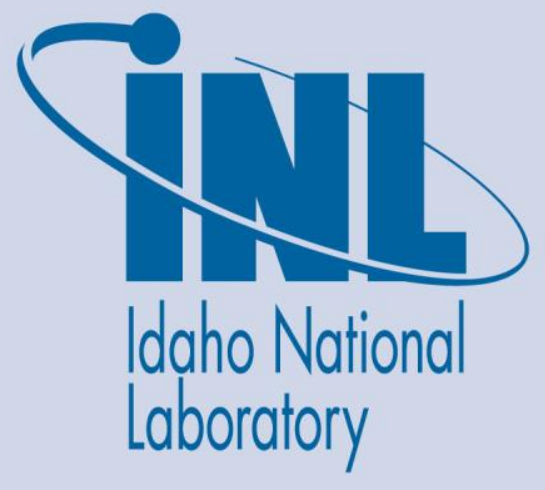

April 2020

The INL is a U.S. Department of Energy National Laboratory operated by Battelle Energy Alliance 


\section{NOTICE}

This information was prepared as an account of work sponsored by an agency of the U.S. Government. Neither the U.S. Government nor any agency thereof, nor any of their employees, makes any warranty, expressed or implied, or assumes any legal liability or responsibility for any third party's use, or the results of such use, of any information, apparatus, product, or process disclosed herein, or represents that its use by such a third party would not infringe on privately owned rights. The views expressed herein are not necessarily those of the U.S. Nuclear Regulatory

Commission. 
INL/EXT-20-57927

\title{
Summary of Nuclear Regulatory Commission Flood Barrier Testing Strategies Workshop
}

\author{
Sai Zhang \\ Zhegang Ma \\ Curtis Smith
}

April 2020

\begin{abstract}
Idaho National Laboratory
Battelle Energy Alliance

Idaho Falls, Idaho 83415
\end{abstract}

\section{http://www.inl.gov}

Prepared for the

Office of Nuclear Regulatory Research

U.S. Nuclear Regulatory Commission

Under U.S. Department of Energy Idaho Operations Office

Contract DE-AC07-05ID14517

NRC Agreement Number 31310019N0006

Task Order Number 31310019F0028 


\begin{abstract}
The United States Nuclear Regulatory Commission (NRC) and Idaho National Laboratory (INL) organized a half-day workshop on flood barrier testing strategies (FBTS) at NRC Headquarters in Rockville, Maryland, via a webinar as well, on March 12, 2020. The workshop was a public meeting attended by members of the public and staff from NRC, INL, and other agencies. The workshop served multiple objectives: (1) present preliminary research results from the FBTS research project conducted by INL for NRC, and (2) engage industry stakeholders and technical experts to provide inputs and insights on testing strategies. This letter report documents the materials presented, participant questions and answers, and summaries of an open discussion during this FBTS workshop.
\end{abstract}




\section{CONTENTS}

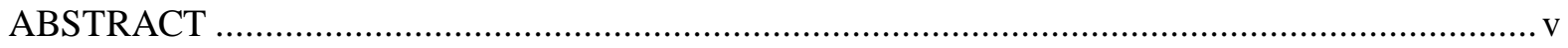

ABBREVIATIONS AND ACRONYMS ........................................................................... vii

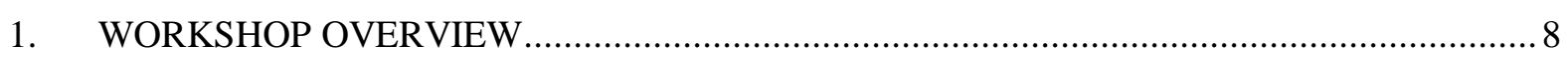

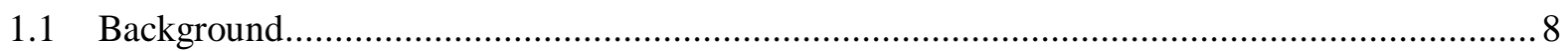

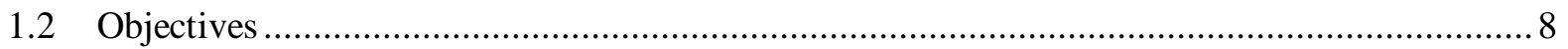

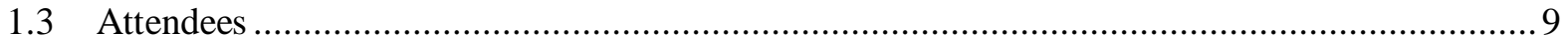

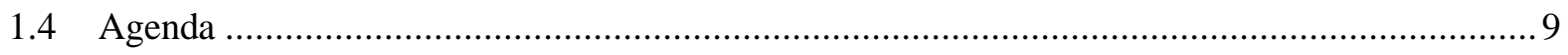

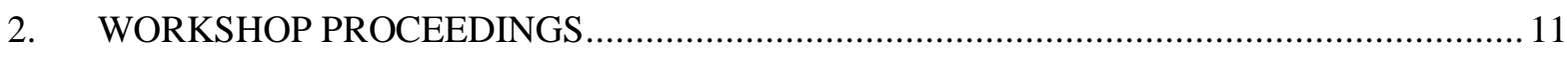

2.1 Overview of Flood Barrier Testing Strategies Research ................................................ 11

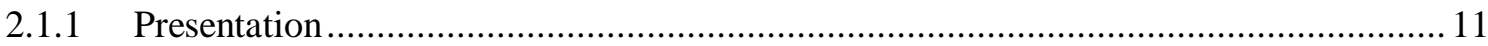

2.2 INL Research on Flood Barrier Testing Strategies and Potential Harvesting ......................... 17

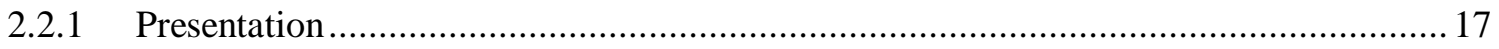

2.3 Preliminary Results of Flood Barrier Testing Strategies Project ........................................ 21

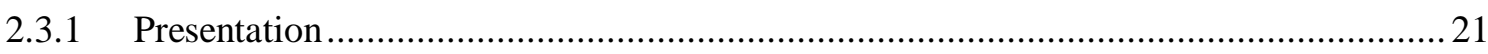

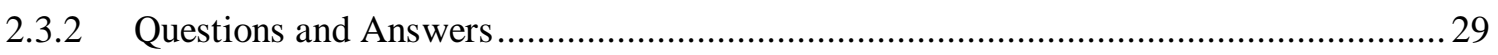

2.4 Literature Review and Previous Flood Barrier Tests ............................................................ 30

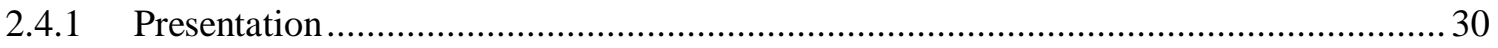

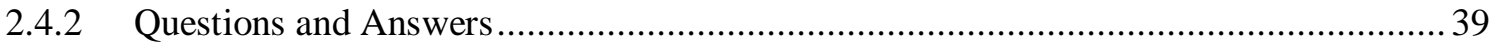

2.5 Flood Rated Penetration Seal Research Overview ............................................................ 40

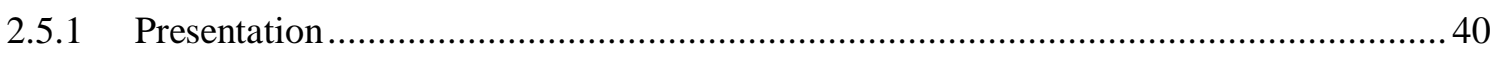

2.6 Flood Barrier Testing Facility - Idaho State University ................................................ 48

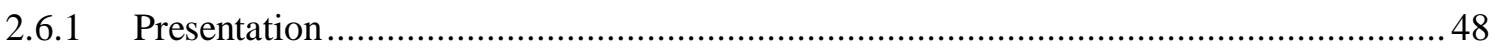

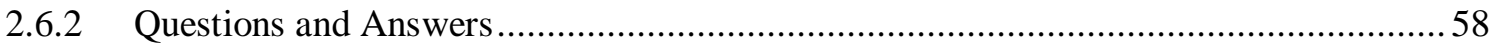

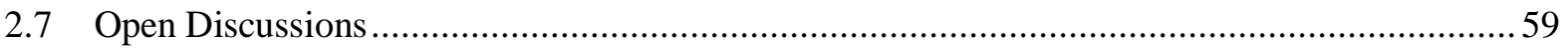

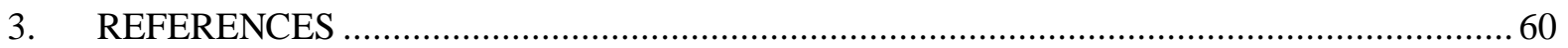




\section{ABBREVIATIONS AND ACRONYMS}

$\begin{array}{ll}\text { ADAMS } & \text { Agencywide Documents Access and Management System } \\ \text { ANS } & \text { American Nuclear Society } \\ \text { ASME } & \text { American Society of Mechanical Engineers } \\ \text { ASTM } & \text { American Society for Testing and Materials } \\ \text { DM } & \text { Degradation Mode } \\ \text { EPRI } & \text { Electric Power Research Institute } \\ \text { ERDC } & \text { Engineering Research and Development Center } \\ \text { ESP } & \text { Early Site Permit } \\ \text { FBTS } & \text { Flood Barrier Testing Strategies } \\ \text { FM } & \text { Failure Mode } \\ \text { FPS } & \text { Flood Penetration Seal } \\ \text { GDC } & \text { General Design Criterion } \\ \text { IN } & \text { Information Notice } \\ \text { INL } & \text { Idaho National Laboratory } \\ \text { IR } & \text { Inspection Report } \\ \text { ISU } & \text { Idaho State University } \\ \text { LER } & \text { Licensee Event Report } \\ \text { NEA } & \text { Nuclear Energy Agency } \\ \text { NEI } & \text { Nuclear Energy Institute } \\ \text { NPP } & \text { Nuclear Power Plant } \\ \text { NRC } & \text { Nuclear Regulatory Commission } \\ \text { NUREG } & \text { NRC technical report designation } \\ \text { OECD } & \text { Organisation for Economic Co-operation and Development } \\ \text { PET } & \text { Portal Evaluation Tank } \\ \text { PFHA } & \text { Probabilistic Flood Hazard Assessment } \\ \text { PRA } & \text { Probabilistic Risk Assessment } \\ \text { SPH } & \text { Smoothed Particle Hydrodynamics } \\ \text { TSCs } & \text { Structures, Systems, and Components } \\ \text { TVA } & \text { Tennessee Valley Authority } \\ \text { United States } \\ \text { United States Army Corps of Engineers } \\ \text { Underwriters Laboratories }\end{array}$




\section{Summary of Nuclear Regulatory Commission Flood Barrier Testing Strategies Workshop}

\section{WORKSHOP OVERVIEW}

\section{$1.1 \quad$ Background}

Flood barriers are a subset of flood protection features. A flood protection feature can be categorized as a flood barrier if it is a device that encloses a particular area to ensure it stays dry (examples include penetration seals and watertight doors). Flood barriers can be used to prevent water from entering nuclear power plant (NPP) areas containing safety-related systems and components. Domestic and international operational experience indicate that performances of flood barriers have significant safety implications. Nuclear industry and United States (U.S.) Nuclear Regulatory Commission (NRC) have appropriate analysis tools for analyzing risk significance of flood barrier performance, i.e., using Probabilistic Risk Assessment (PRA) models, but performance or reliability data on in-service components is lacking.

To fill this gap, the NRC initiated a research project, "Flood Barrier Testing Strategies (FBTS)" as part of their Probabilistic Flood Hazard Assessment Research Program. Under this project, NRC engaged Idaho National Laboratory (INL), and Idaho State University (ISU) as a subcontractor, to identify and assess options and develop strategies for testing flood barriers at decommissioned NPPs. This project aims to review available information on FBTS and assess the (1) current state of NPP decommissioning for potential harvesting, (2) technical and logistical considerations and challenges to harvesting and laboratory testing of flood barriers, and (3) potential alternatives to harvesting, such as in-situ testing and enhanced inspection.

\subsection{Objectives}

One of the tasks under the FBTS research project requires INL to assist NRC in organizing and conducting an FBTS workshop, which aims to bring together industry stakeholders to discuss options and strategies for flood barrier testing at decommissioned NPPs to obtain reliability data to better inform flood risk assessments. This NRC FBTS workshop was held at NRC Headquarters in Rockville, Maryland, via a webinar as well, on March 12, 2020. The workshop was an open meeting attended by members of the public, NRC technical staff, management, and contractors, and staff from INL, ISU, and other agencies. The workshop served multiple objectives: (1) presenting preliminary research results from the FBTS research project, and (2) engaging industry stakeholders and technical experts to provide inputs and insights on testing strategies.

\subsection{Outline}

This letter report summarizes the NRC FBTS workshop presentations and discussions. The remaining of this section presents the workshop attendee list and agenda. Section 2 provides the presentation material for the workshop, which began with brief self-introductions by all attendees, followed by opening remarks and an overview of FBTS research by Joseph Kanney and Thomas Aird from NRC. Curtis Smith from INL introduced research conducted by INL on FBTS and potential harvesting. Following the introduction session, several technical presentations were provided by staff from INL, Fisher Engineering, Inc., and ISU. The workshop concluded with an open discussion. Section 3 presents a summary of the workshop along with the follow-up actions for the research. 


\section{$1.4 \quad$ Attendees}

A list of workshop attendees ${ }^{1}$ is provided as follows:

- Andrew Kalukin (National Geospatial-Intelligence Agency)

- Brenden Overton (NuScale Power)

- Chad L. Pope (ISU)

- Curtis L. Smith (INL)

- Frances Pimentel (Nuclear Energy Institute [NEI])

- Jacob Philip (NRC)

- Jeff Greene (Electric Power Research Institute [EPRI])

- Jim Heishman (EPRI)

- Joseph Kanney (NRC)

- Joshua B. Lacy (Tennessee Valley Authority [TVA])

- Karen Carboni (TVA)

- Kit Ng (Bechtel Corporation)

- Mark Thaggard (NRC)

- Meredith Carr (NRC)

- Michelle (Shelby) Bensi (University of Maryland)

- Ray Schneider (Westinghouse Electric Company)

- Robert Azimi (FM Approvals)

- Sai Zhang (INL)

- Thomas Aird (NRC)

- Tim Schmitt (Framatome)

- W. Mark Cummings (Fisher Engineering, Inc.)

- Zhegang Ma (INL)

\section{$1.5 \quad$ Agenda}

Date and Time: $\quad$ March 12, 2020, 13:00-17:00 EDT

Location: $\quad$ NRC Headquarters, Rockville, Maryland (via webinar as well)

\section{Thursday, March 12, 2020}

\begin{tabular}{|l|l|l|}
\hline Time & Topic & Presenter \\
\hline 13:00-13:15 & Welcome \& Introductions & $\begin{array}{l}\text { NRC Office of Nuclear } \\
\text { Regulatory Research }\end{array}$ \\
\hline 13:15-13:30 & Overview of FBTS Research & NRC - Thomas Aird \\
\hline 13:30-13:55 & INL Research on FBTS and Potential Harvesting & INL - Curtis L. Smith \\
\hline 13:55-14:20 & FBTS Project Overview & INL - Zhegang Ma \\
\hline 14:20-14:45 & Literature Review and Previous Flood Barrier Tests & INL - Sai Zhang \\
\hline 14:45-15:00 & Break & \\
\hline 15:00-15:25 & Flood Penetration Seal Testing & $\begin{array}{l}\text { Fisher Engineering, Inc. }- \text { W. } \\
\text { Mark Cummings }\end{array}$ \\
\hline
\end{tabular}

${ }^{1}$ A significant amount of workshop attendees participated from online. The list may not be complete as some online participants did not register to the meeting and did not display their names on the webinar. 


\begin{tabular}{|l|l|l|}
\hline 15:25-15:50 & Flood Barrier Testing Facility - Idaho State University & ISU - Chad L. Pope \\
\hline $15: 50-17: 00$ & Open Discussions & \\
\hline \hline $17: 00$ & Adjourn & \\
\hline
\end{tabular}




\section{WORKSHOP PROCEEDINGS}

2.1 Overview of FBTS Research

Presented by Thomas Aird (NRC)

\subsubsection{Presentation}

\section{Welcome}

Flood Barriers Testing Strategies Public Meeting

NRC HQ, Rockville, MD

March 12, 2020

Room Audio: call 888-748-8559 participant passcode: 79389 press ${ }^{*} 6$ to mute your phone line 


\section{Evacuation}

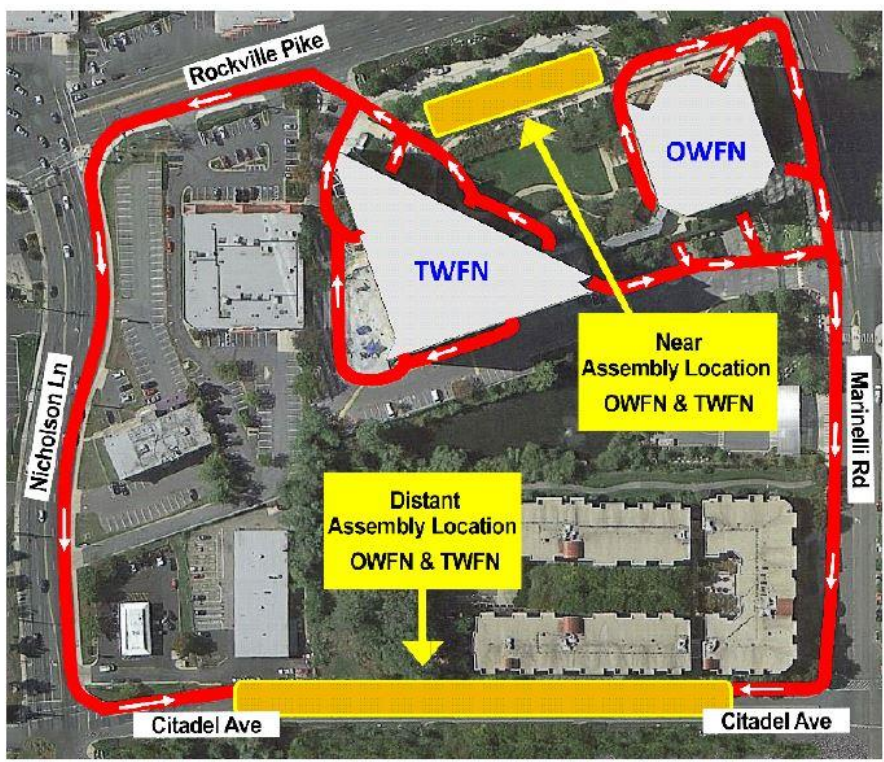

Room Audio: call 888-748-8559 participant passcode: 79389 press ${ }^{*} 6$ to mute your phone line

\section{Talking Points}

Present preliminary research results from the INL-NRC project including:

- An overview of flood barriers in the project scope

- A review of potential flood barrier testing facilities, including decommissioning plants for potential harvesting

We are seeking input and insights on testing strategies for flood barriers 


\section{Regulatory Context}

- The regulatory criterion for protection of structures, systems, and components (SSCs) important to safety against natural phenomena is provided in 10 CFR Part 50 Appendix A, General Design Criterion (GDC) 2 "Design bases for protection against natural phenomena". GDC-2 states that SSCs important to safety shall be designed to withstand the effects of natural phenomena that have been historically reported for the site and surrounding area, with sufficient margin for the limited accuracy, quantity, and period of time in which the historical data have been accumulated. The regulation also states that the design bases shall reflect appropriate combinations of the effects of normal and accident conditions with the effects of the natural phenomena.

- The requirements for the contents of applications for new reactors is provided in 10 CFR Part 52, more specifically 10 CFR Part 52.17 (a)(1)(vi), for early site permits (ESPs) and 10 CFR Part 52.79 (a)(1)(iii), for combined licenses as they relate to the hydrologic characteristics of the proposed site with appropriate consideration of the most severe of the natural phenomena that have been historically reported for the site and surrounding area and with sufficient margin for the limited accuracy, quantity, and period of time in which the historical data have been accumulated.

\section{Technical Context}

- The most common flood protection features are seals for penetrations in external walls (and internal walls) of safety related structures that allow cables, conduits, cable trays, piping etc., to pass through the walls. Other flood protection features include water-tight doors, as well as temporary flood barriers (e.g., temporary walls, stop-logs).

- Operational experience (domestic and international) provides clear indication that flood barrier performance may have significant safety implications, especially as reactor fleet ages. Performance of flood protection features at NPPs has been ongoing safety issue for some time.

- Industry and NRC have appropriate analysis tools for addressing the risk-significance of flood barrier performance (i.e. PRA models), but basic performance/reliability data on in-service components is lacking. This research project will identify and assess options and develop strategies for testing NPP flood barriers. 


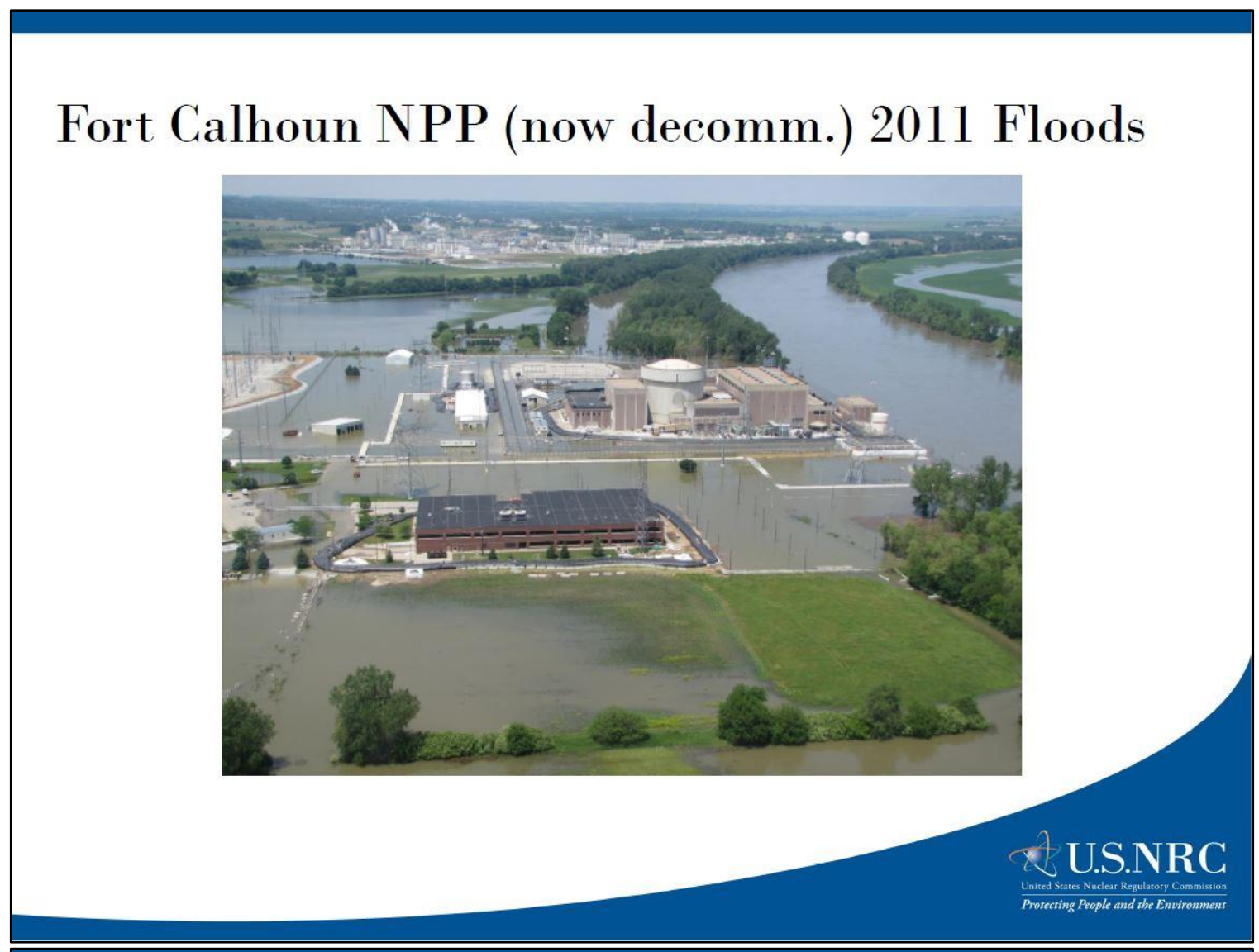

Fort Calhoun NPP (now decomm.) - 2011 Flooding Event - Flooded Conduits

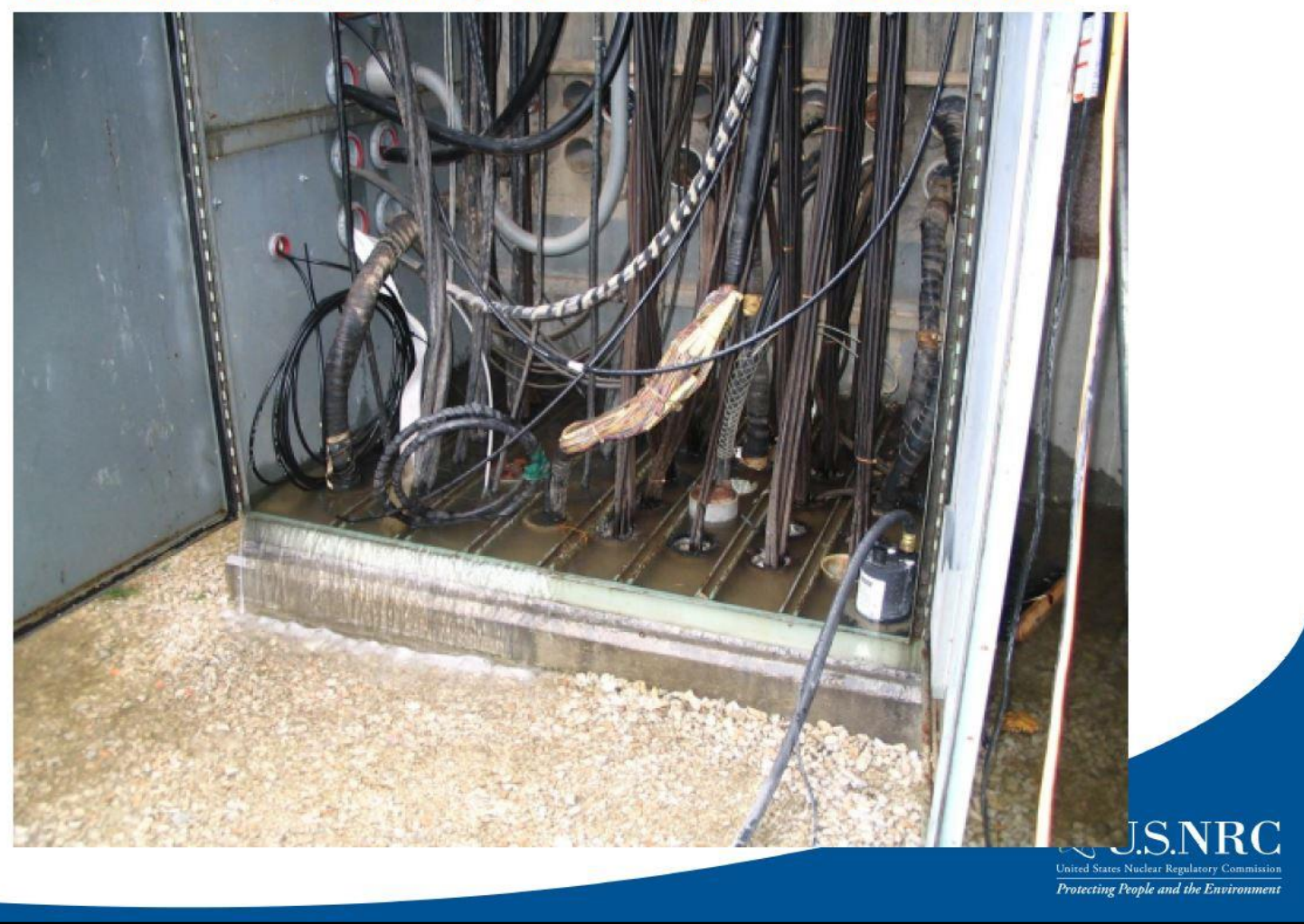




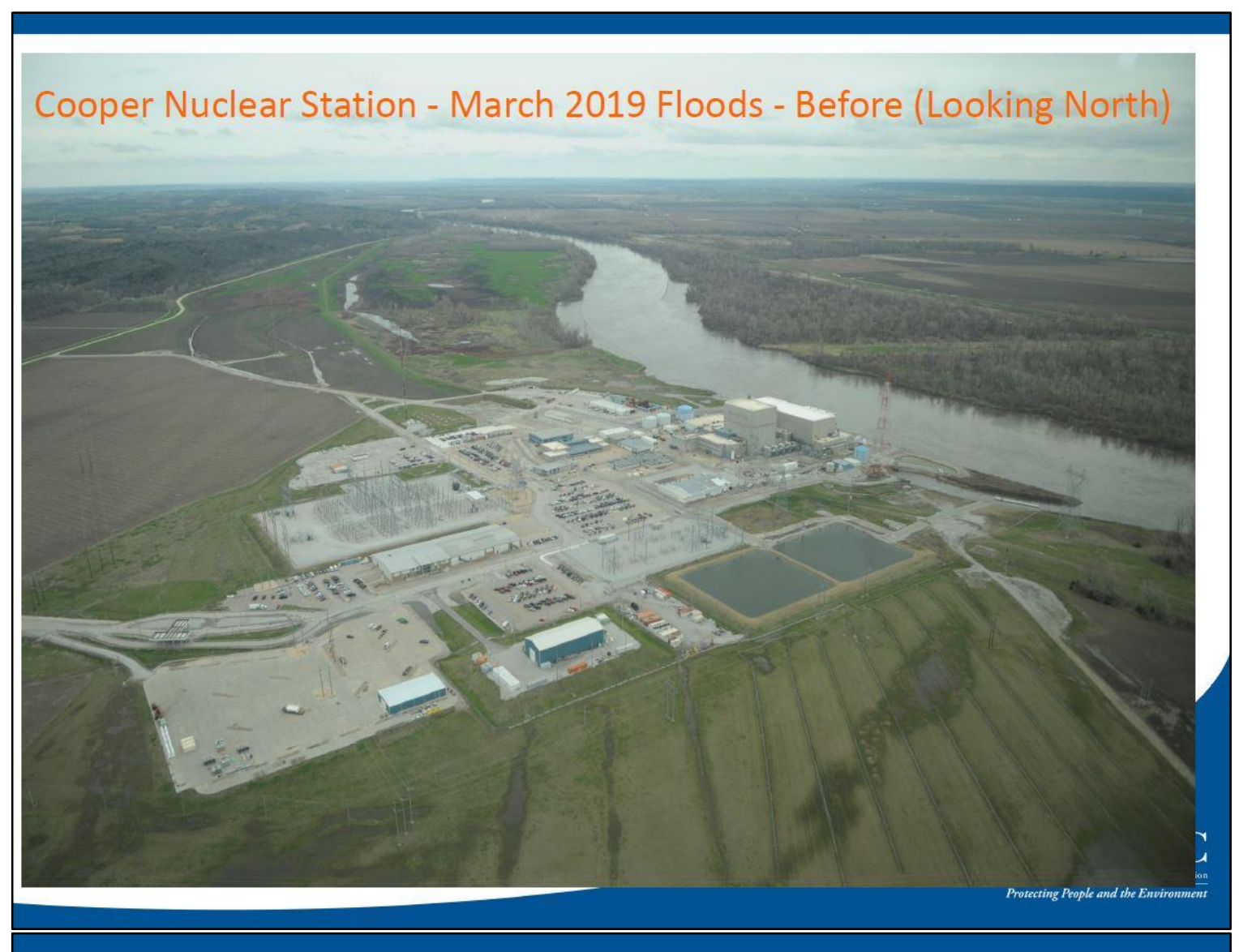

Cooper Nuclear Station - March 162019 Floods- After (Looking North)

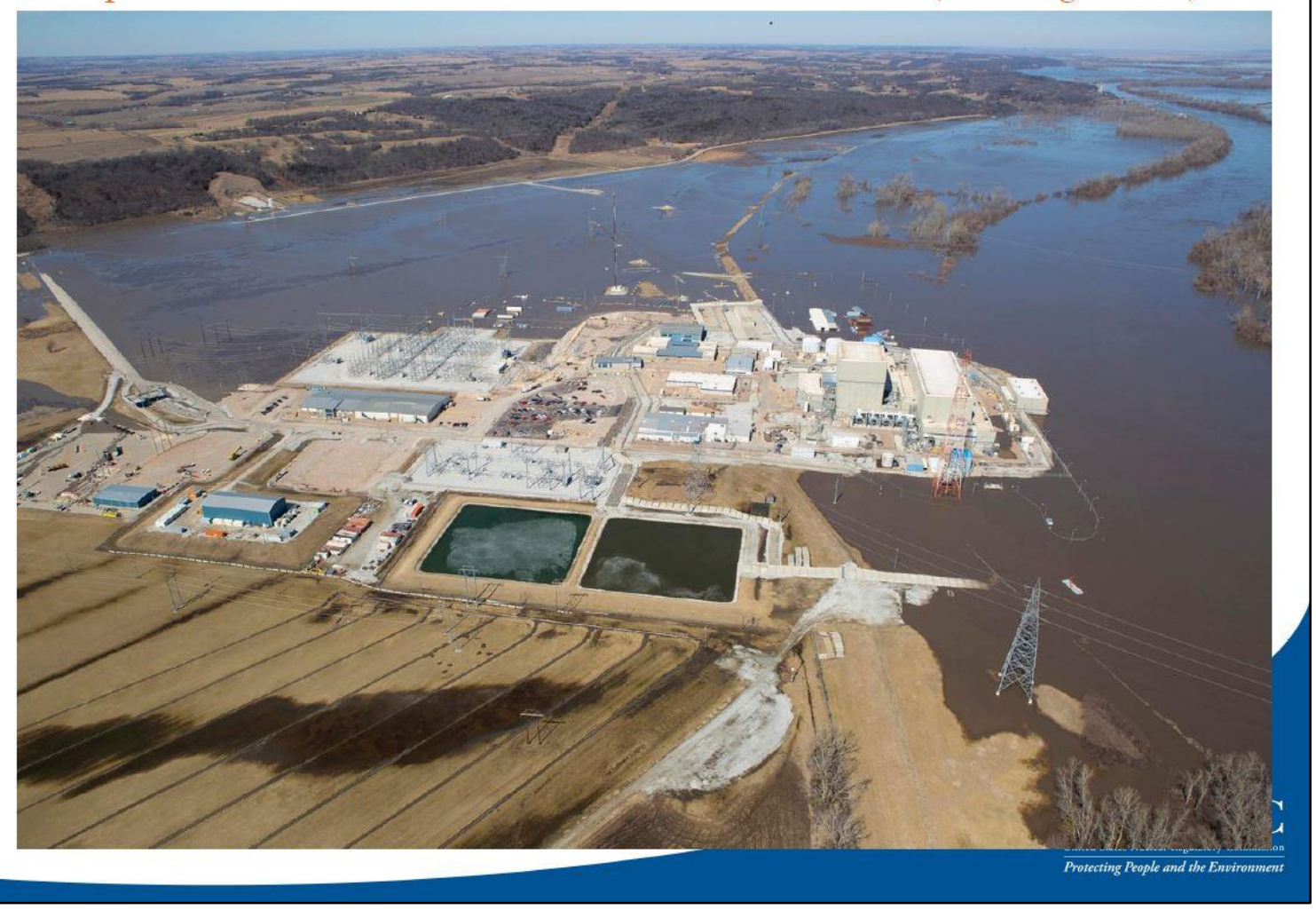




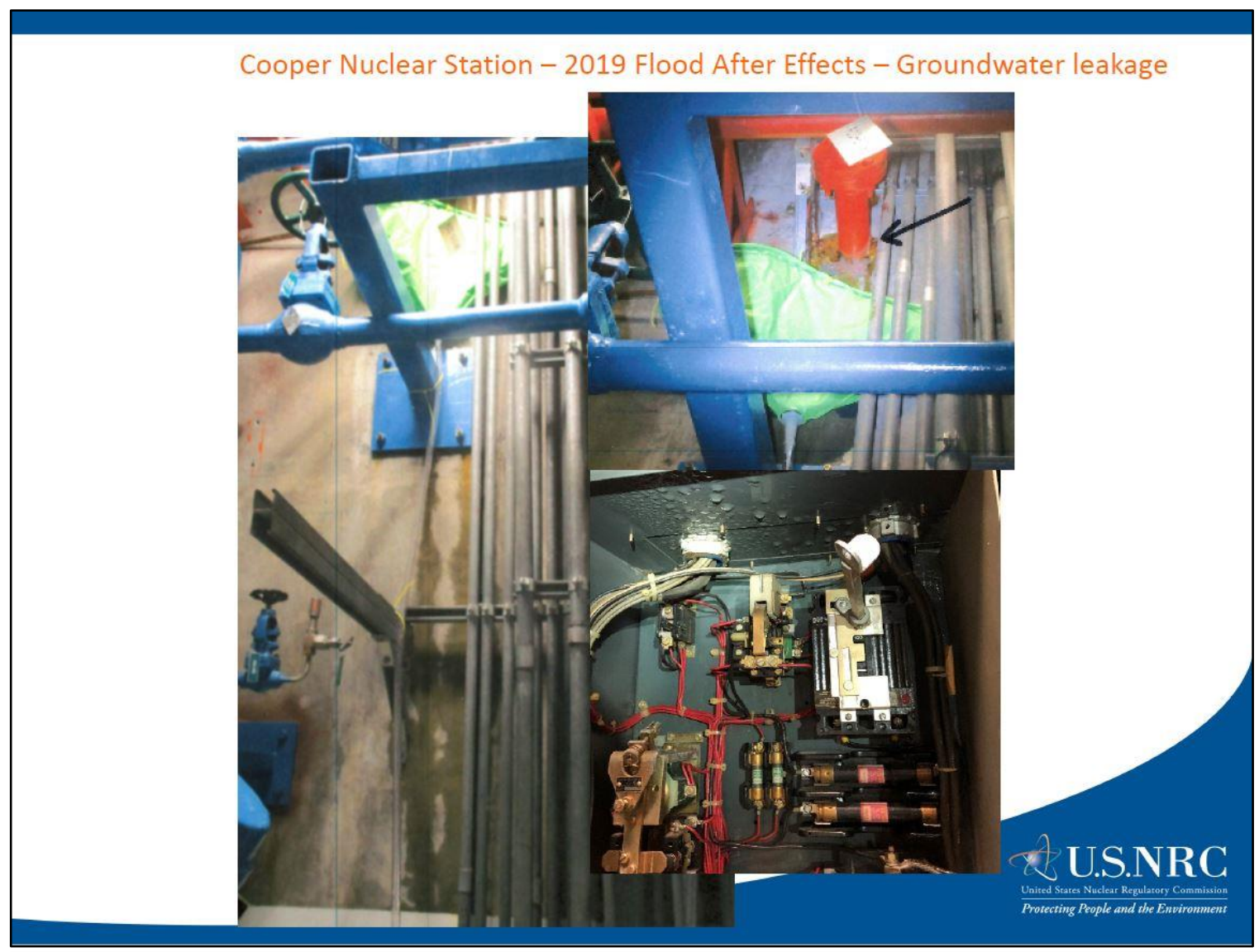

St. Lucie Nuclear Power Plant - 2011 Flooding Event - Video

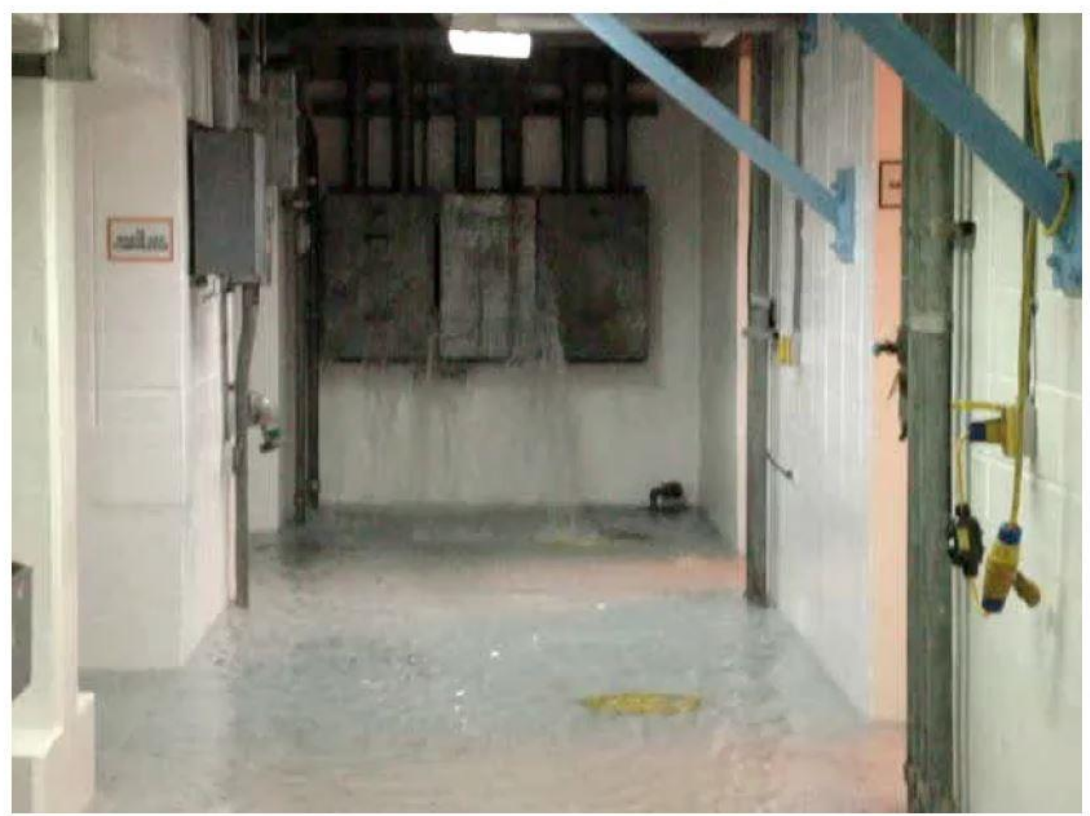


2.2 INL Research on FBTS and Potential Harvesting

Presented by Curtis L. Smith (INL)

\subsubsection{Presentation}

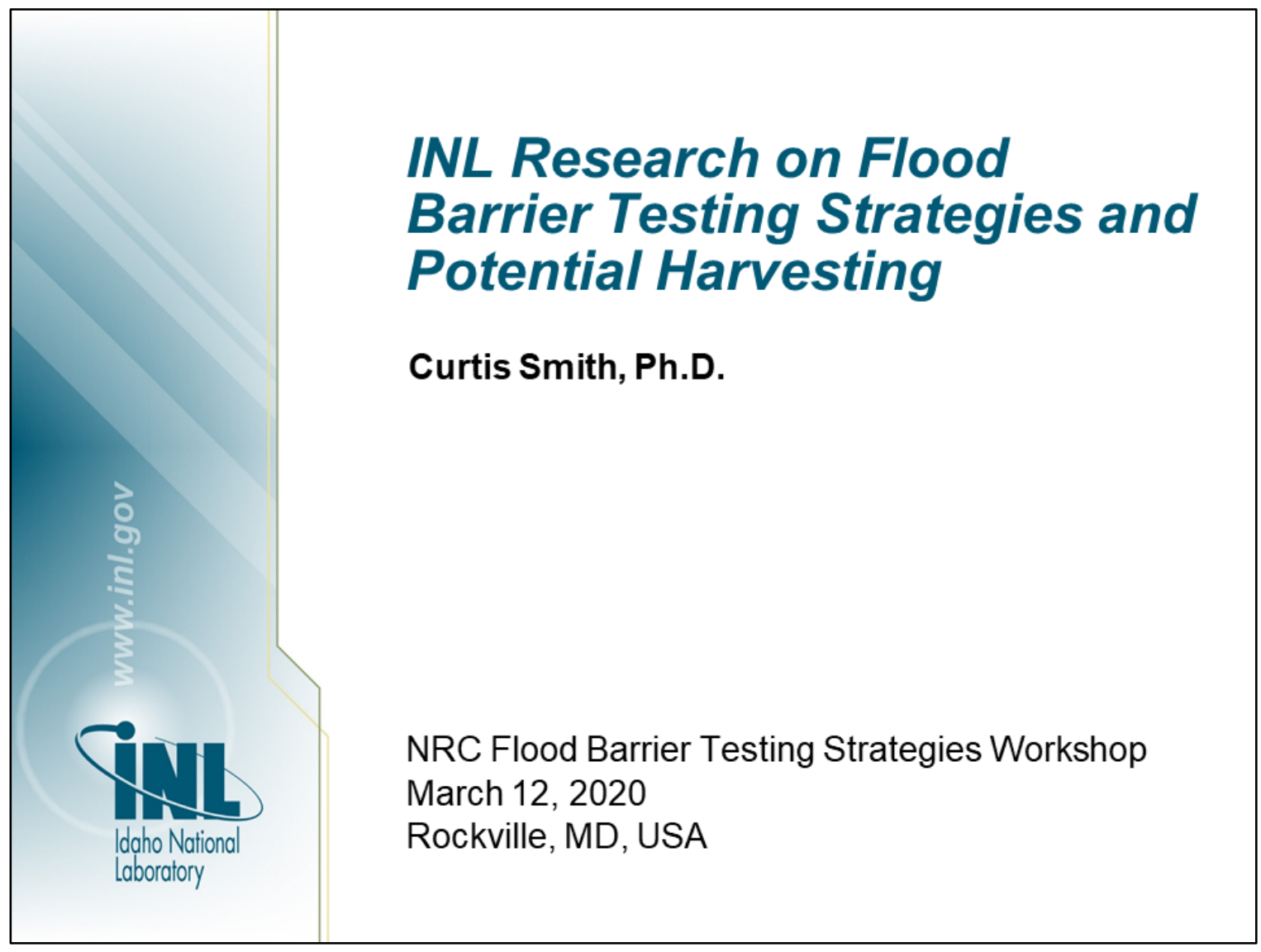




\section{Introduction}

$>$ Flood barriers are part of the nuclear power plant (NPP) flood protection features

$>$ Prevent

$>$ Mitigate

$>$ Performance of flood protection features, including flood barriers at NPPs, has long been an ongoing safety issue

Flood barriers should be tested, inspected, and maintained to perform intended functions

$>\mathrm{INL}$ is conducting research to support the NRC

$>$ Develop flood barrier testing strategies

$>$ Explore potential harvesting for flood barrier test

\section{Project Team}

INL

$>$ Curtis Smith, PI

Zhegang Ma

$>$ Sai Zhang

$>$ John Biersdorf

> Idaho State University

> Chad Pope, Professor 


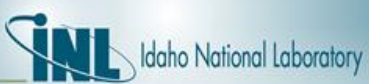

\section{Project Status}

> Task 1: Review Available Information on Flood Barriers

$>$ Licensee walkdown reports

$>$ Previous NRC research

$>\mathrm{NEI}, \mathrm{EPRI}$ reports

$>$ Vendors info

$>$ Decommissioning info

$>$ Other government agencies (e.g., USACE)

$>$ International (e.g., NEA)

$>$ Status - Task report drafted, reviewed, and revised

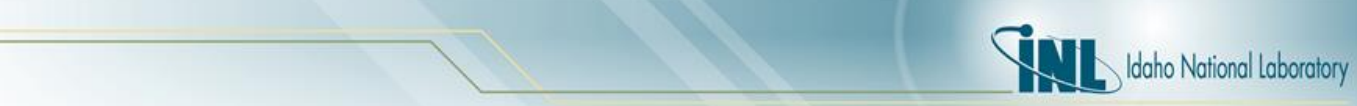

\section{Project Status (cont.)}

Task 2: Flood Barrier Testing Workshop

$>$ Present preliminary results from the project

$>$ Engage industry stakeholders and technical experts to provide inputs and insights

Status - Ongoing

> Task 3: International Harvesting Workshop

$>$ Cancelled

$>$ Task 4: Knowledge Transfer

$>$ Participate the NRC PFHA Research Workshop-Completed

> Prepare a draft NUREG/CR report - 9/15/2020 


\section{Project Preliminary Results}

$>$ Project preliminary results to be presented in this workshop

$>$ Literature Review

Flood Barrier Categorization and Terminology

> Flood Barrier Overview

> Potential Flood Barrier Testing Facilities

$>$ Visited a decommissioning plant in November 2019

$>$ Conducted walkdown on flood barriers

Flood Barrier Testing Strategies
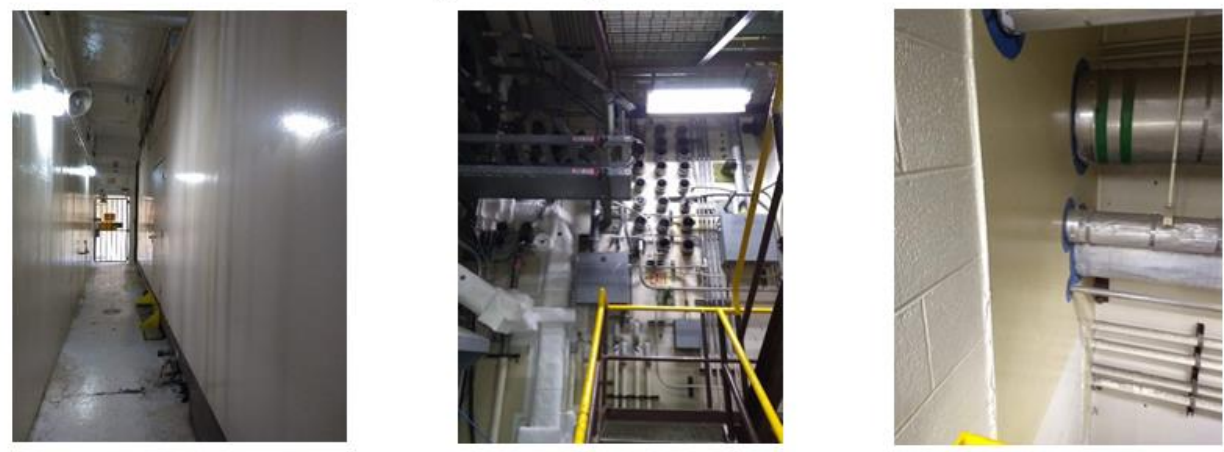

\section{Research is Ongoing}

We want to engage industry stakeholders and technical experts for insights and inputs

$>$ During the workshop

$>$ After the workshop

Thomas.Aird@nrc.gov

Curtis.Smith@inl.gov

Zhegang.Ma@inl.gov 


\subsection{Preliminary Results of FBTS Project}

Presented by Zhegang Ma (INL)

\subsubsection{Presentation}

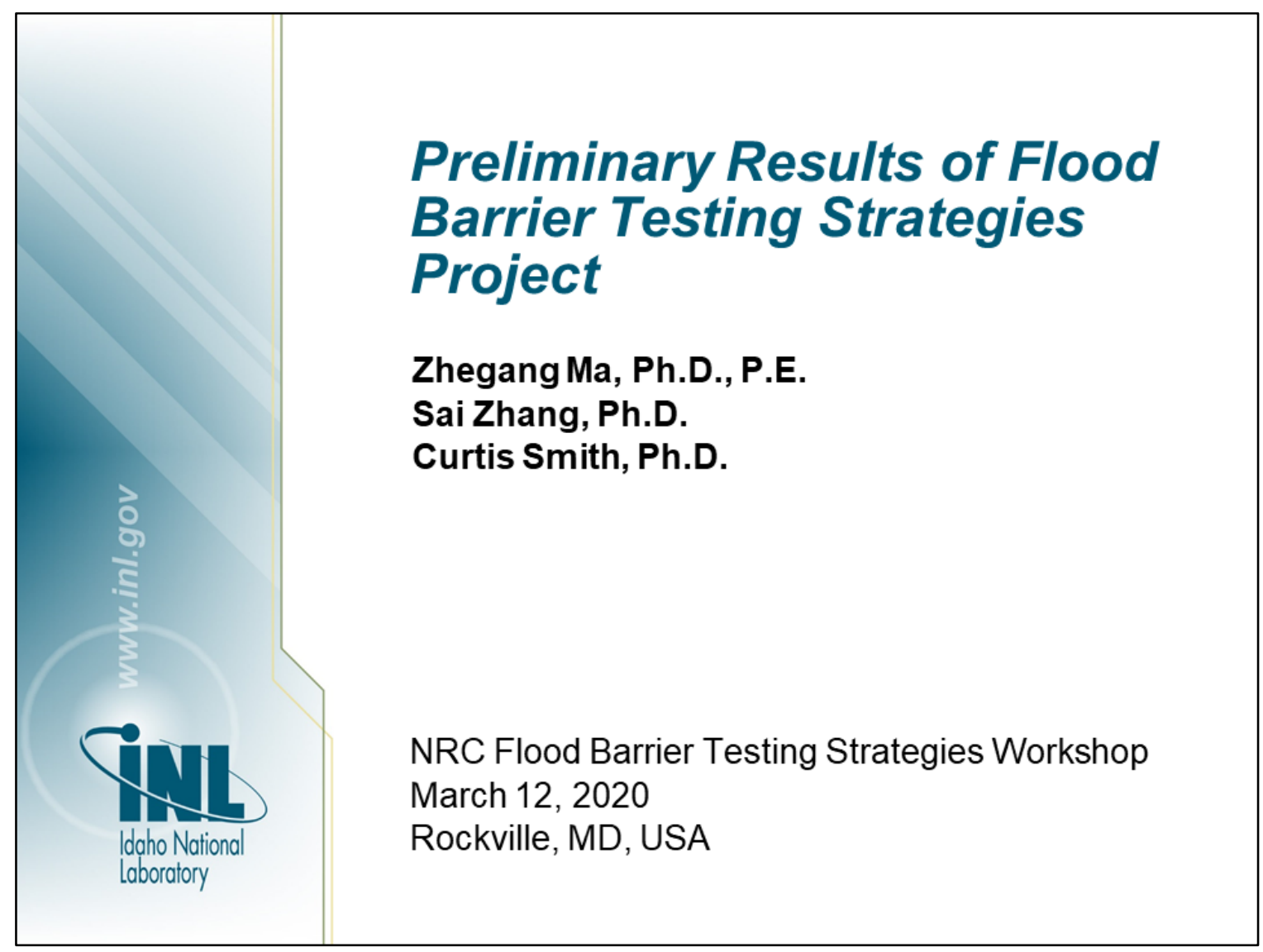




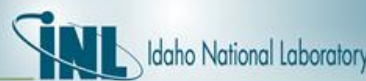

\section{Background}

Flood barriers are part of the nuclear power plant (NPP) flood protection features that prevent structures, systems, and components (SSCs) from experiencing flooding and mitigate the effects of flooding

Flood barriers can be on-site or off-site, permanent or temporary, active or passive

- Permanent: external and internal walls, watertight doors, and flood penetration seals

> Temporary: sandbags, temporary walls, removable doors, and stop-logs
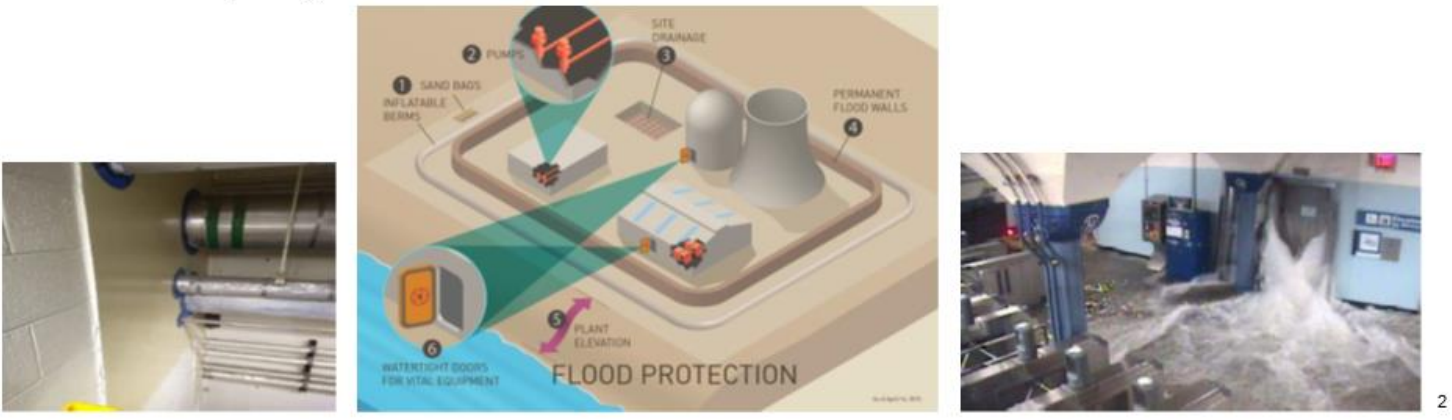

\section{Background (cont.)}

Operational experiences have shown that flood barrier performance could have significant safety implications, especially as the domestic reactor fleet ages

$>$ Inadequate design or installation

$>$ Non-functional due to aging and degradation

$>$ Inadequate inspection procedures or acceptance criteria for detecting deficient flood barriers

$>$ Deficient analyses associated with flood barriers

$>$ Discrepancies between tested flood barrier designs and plantinstalled designs

$>$ Installed barriers modified but not evaluated or tested

$>$ Deficient flood barriers due to lack of fill or being composed of non-watertight materials

- Missing penetration seals or internal conduit seals 


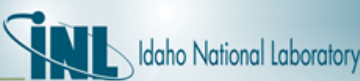

\section{Background (cont.)}

Flood barriers must be adequately tested, inspected, and maintained to provide reasonable assurance that they can perform their intended functions in the event of flooding

Project objective: to identify and assess options and develop strategies for testing NPP flood barriers

$>$ Investigate the current state of NPP decommissioning which impacts opportunities and challenges for harvesting

$>$ Consider technical and logistical challenges in harvesting and laboratory testing of flood barriers

$>$ Potential alternatives to harvesting, such as in-situ testing, enhanced inspection

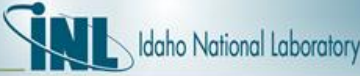

\section{Project Status}

Task 1: Review Available Information on Flood Barriers

$>$ Licensee walkdown reports

- Previous NRC research

> Nuclear Energy Institute (NEI), Electric Power Research Institutes (EPRI) reports

$>$ Information from vendors

$>$ Decommissioning info

> Other government agencies (e.g., U.S. Army Corps of Engineers)

$>$ International organizations (e.g., Nuclear Energy Agency)

- Status - Task report drafted, reviewed, and revised 


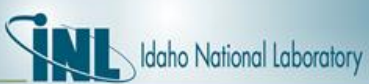

\section{Project Status (cont.)}

> Task 2: Flood Barrier Testing Workshop

$>$ Present preliminary results from the project

$>$ Engage industry stakeholders and technical experts to provide inputs and insights

Status - Ongoing

> Task 3: International Harvesting Workshop

$>$ Cancelled

$>$ Task 4: Knowledge Transfer

> Participate the NRC PFHA Research Workshop - Completed

> Prepare a draft NUREG/CR report - 9/15/2020

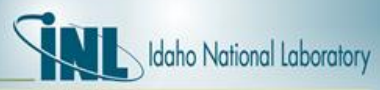

\section{Project Preliminary Results}

Literature Review (presented separately)

$>$ Including plant flooding walkdown report review

Flood Barrier Categorization and Terminology

$>$ Flood Barrier Overview

$>$ Potential Flood Barrier Testing Facilities

$>$ Previous Flood Barrier Tests (presented separately)

Flood Barrier Testing Strategies

$>$ Considerations in developing flood barrier testing strategies 


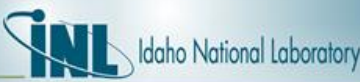

\section{Flood Barrier Overview}

$>$ Categorization

$>$ On-site vs. Off-site

$>$ Permanent vs. Temporary

Active vs. Passive

$>$ On-site Permanent

$>$ Penetration Seals

$>$ Watertight Doors

$>$ On-site Temporary
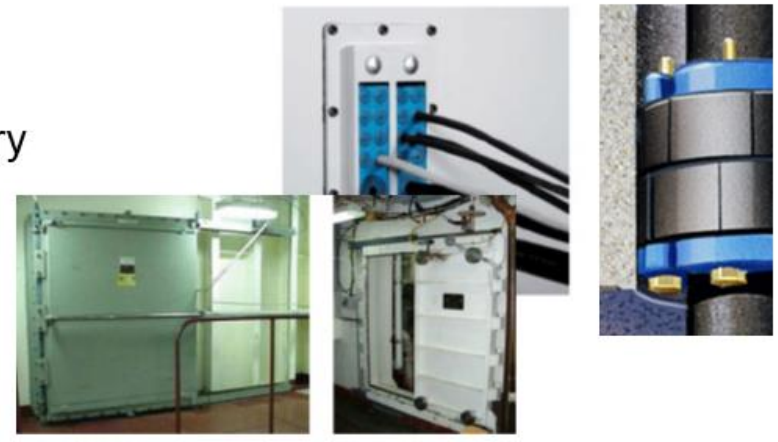

$>$ Disposable - absorbent pad, etc.

$>$ Reusable - floodgates, hydrostatic tarp, etc.
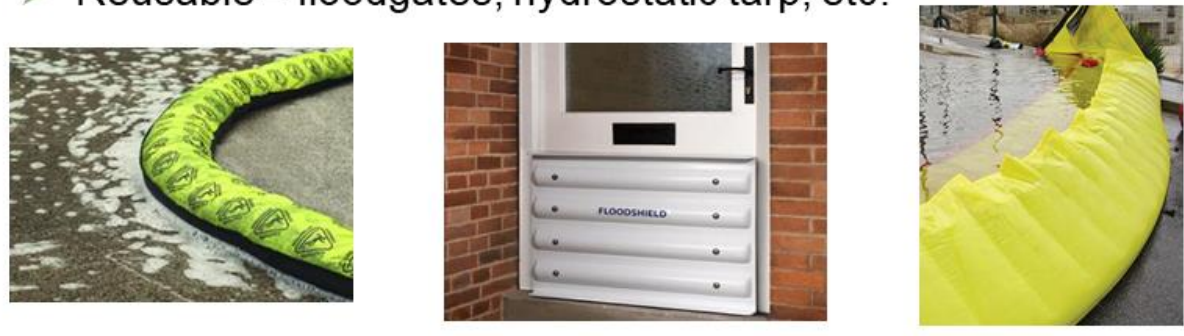

\section{Tiv. Idoho National laboratory}

\section{Potential Flood Barrier Testing Facilities}

\section{$>$ Operating Plants}

$>$ Nearly 100 licensed NPPs in the United States

$>$ Potential testing facilities for in-situ non-destructive testing or enhanced inspection

$>$ Testing must be carefully incorporated into plant's schedule to avoid inadvertently impacting the safety and reliability of plant operations

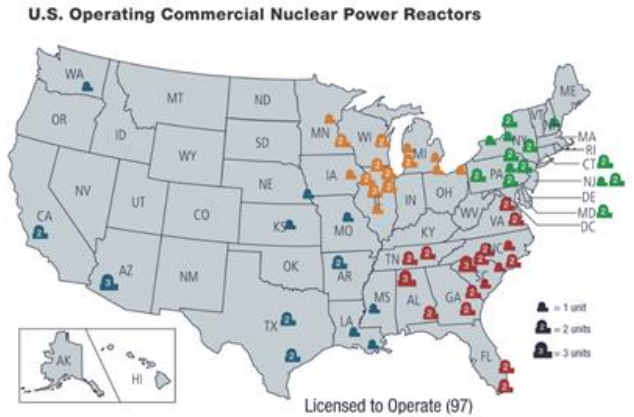




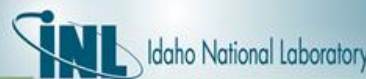

\section{Potential Flood Barrier Testing Facilities (Cont.)}

$>$ Decommissioning Plants

$>$ About 20 power reactors undergoing decommissioning

\section{Major Decommissioning Companies}

- Holtec Decommissioning International (HDI)

$>$ Oyster Creek, Pilgrim

> Purchase agreements for Palisades and Indian Point

\section{NorthStar}

$>$ Vermont Yankee

\section{EnergySolutions}

$>$ Zion and La Crosse

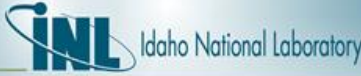

\section{Potential Flood Barrier Testing Facilities (Cont.)}

Other Testing Facilities - Idaho State University Flood Testing Facility

$>$ Portal Evaluation Tank (PET)

$>$ A steel, semi-cylindrical tank with a height and diameter of $8 \mathrm{ft}$, can hold up to 2,000-gal of water

- 5 HP submersible pump inside a 8,000-gal water reservoir

> Inlet electromagnetic flow meter, ultrasonic depth sensor, and pressure transducer, pressure and air relief valves and a digital pressure gauge
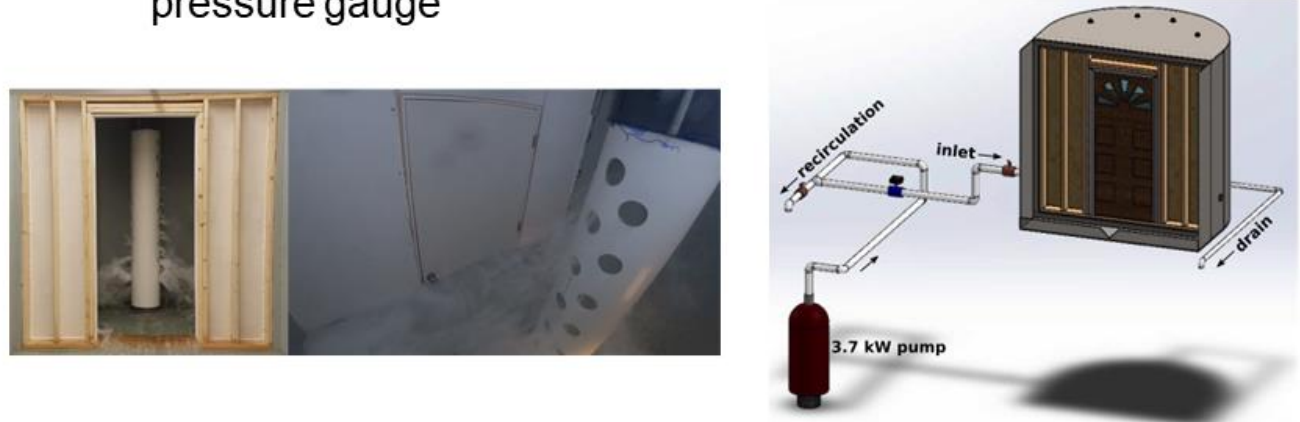


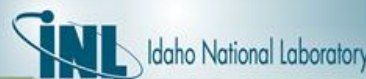

\section{Potential Flood Barrier Testing Facilities (Cont.)}

Other Testing Facilities - Framatome Laboratory Flood Testing Facility

$>$ Test apparatus for research on penetration seal testing protocol

$>$ Three main components

$>$ Pressure chamber

$>$ Concrete test deck

$>$ Water leakage measurement system
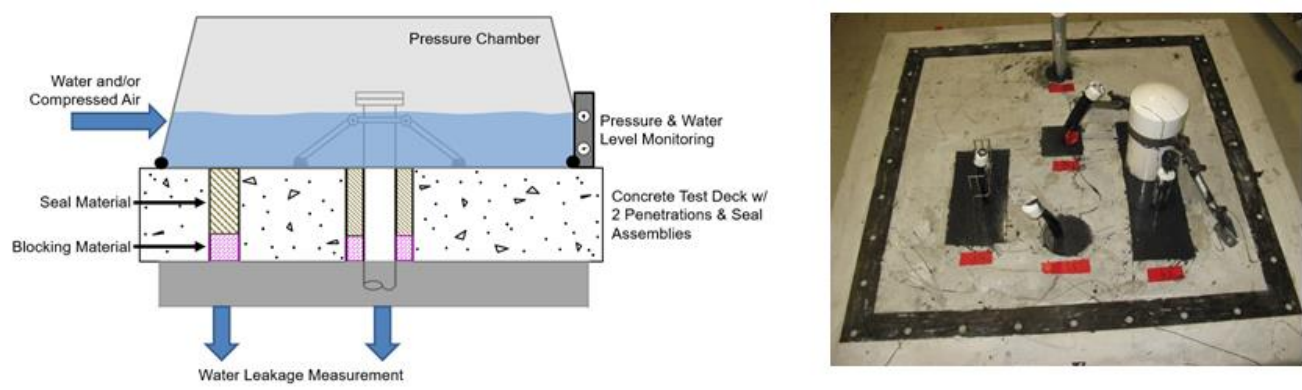

\section{IMIL}

\section{Flood Barrier Testing Strategies Considerations}

What to be tested?

$>$ Hundreds of flood barriers

$>$ Risk/Safety ranking

$>$ Location (i.e., Accessibility)

$>$ Type of Flood Barriers for Testing

$>$ Seals, Doors, Walls, Floors, Temporary Barriers

\section{$>$ Codes and Standards}

$>$ Penetration Seals

$>$ UL 1479 and UL 2079 for pressure testing of fire barriers

$>$ Doors

Door testing standards, e.g., ASTM E331

$>$ Analytical methods

Base Structures 


\section{Till anteribion}

\section{Flood Barrier Testing Strategies (Cont.)}

$>$ Protocols and Plans

$>$ Testing Locations

$>$ In-situ (in plant, in place)

Ex-situ but on-site (not in place, but on-site)

$>$ Ex-situ and off-site (off-site testing facilities)

\section{Flood Effect and Failure Modes}

$>$ Hydrostatic pressure, hydrodynamic pressure, debris impact

$>$ Excessive leakage, loss of integrity, displacement,

\section{Mediums} overtopping

$>$ Water, air, steam

$>$ Standing (without pressure) - static pressure testing

$>$ Under pressure (via pump or air) - dynamic pressure testing

\section{Idaho National Laboratory}

\section{Flood Barrier Testing Strategies (Cont.)}

\section{Protocols and Plans}

\section{Parameters}

Input Parameters: test pressure, water levels, flow rate, duration of applied pressure, rate of pressure change, debris size

$>$ Output Parameters: leakage rate, maximum pressure before loss of integrity

$>$ Other Parameters: water temperature, test duration, time history

\section{Acceptance Criteria}

$>$ In accordance with the functional requirements

$>$ No/negligible leakage, maintained integrity under static and/or dynamic pressure

\section{Other aspects}

$>$ Destructive vs non-destructive, sample vs actual flood barriers 


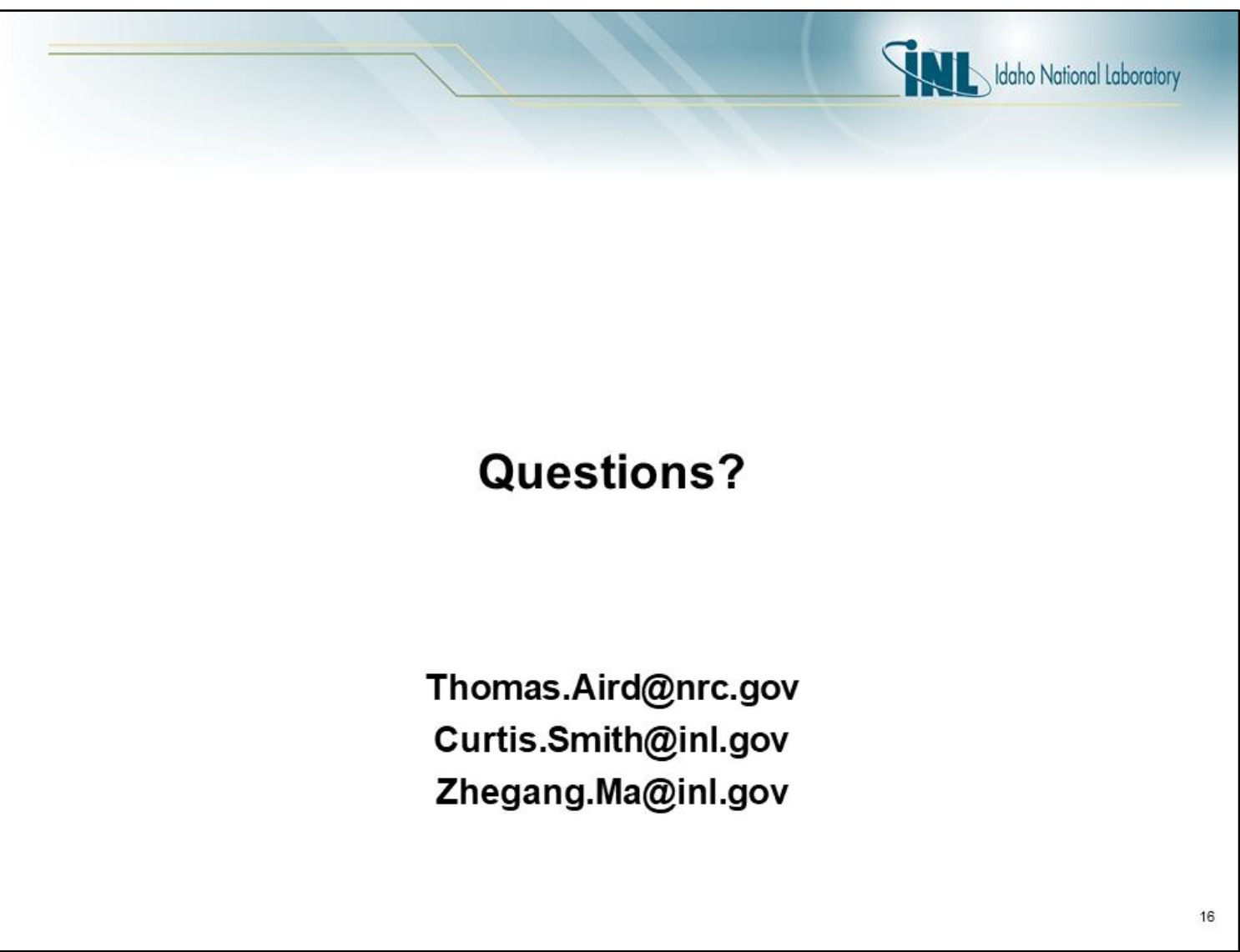

\subsubsection{Questions and Answers}

Question: What does "lack of fill" mean in Slide 3?

Answer: It refers to missing seals or non-watertight seals which should be watertight.

Question: Are you considering building new testing laboratories?

Answer: This is not included in the current scope of this project.

Question: How high are the water levels (e.g., 1 meter, 2 meter, or 3 meter) that you are looking at for testing?

Answer: This project mainly focuses on identifying structures, systems, and components (SSCs) credited in flooding hazard, selecting SSCs for testing, and gathering available information on determining testing conditions for selected SSCs. Detailed information related to testing facilities and conditions of previous flood barrier tests will be introduced later in other presentations of this workshop.

Question: How do you test large structures (e.g., a concrete wall)?

Answer: We have not yet conducted such tests or included this type of tests in the literature review. Some civil engineering laboratories may be capable to test large structures.

Question: Can flood barrier testing help determine the effects of aging and environmental exposure (e.g., temperature and moisture)?

Answer: This would be an interesting topic to look at. These factors could indeed pose an impact on flood barrier performance. For instance, if a flood barrier is installed at different locations, its performance can be quite different. Also, we should be aware that differences exist between ex-situ testing conditions and in-situ field conditions. 


\subsection{Literature Review and Previous Flood Barrier Tests}

\subsubsection{Presentation}

Presented by Sai Zhang (INL)

\section{Literature Review and Previous Flood Barrier Tests}

Sai Zhang, Ph.D.

Zhegang Ma, Ph.D., P.E.

Idaho National Laboratory

NRC Flood Barrier Testing Strategies Workshop March 12, 2020

Rockville, MD USA 


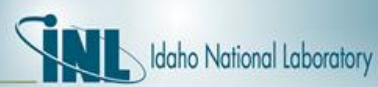

\section{Presentation Outline}

\author{
Literature Review
}

Plant-Specific Flood Barrier Types and Performances

$>$ Examples of Previous Flood Barrier Tests

\section{Literature Review}

\section{Reviewed Materials from a Variety of Sources}

\section{Domestic Agencies}

- United States Nuclear Regulatory Commission (NRC)

- United States Army Corps of Engineers (ACE)

$\square$ International Agency

- Organisation for Economic Co-operation and Development Nuclear Energy Agency (OECD NEA)

\section{Industry and Academia}

- Nuclear Energy Institute (NEI)

- Electric Power Research Institute (EPRI)

- Licensee flooding walkdown reports

- Nuclear power plant (NPP) decommissioning information

- Idaho National Laboratory (INL) and Idaho State University (ISU)

- Relevant publications in scientific journals and conferences

- Publicly available information from flood barrier vendors 


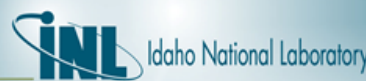

\section{Literature Review (cont.)}

\section{List of Reviewed Materials}

\section{NRC}

- Materials Related to Flood Barriers

- Regulatory Guide 1.102, Rev. 1, "Flood Protection for Nuclear Power Plants," 1976

- Japan Lessons-learned Project Directorate, Interim Staff Guidance, JLDISG-2012-05, Rev.0, "Guidance for Performing the Integrated Assessment for External Flooding," 2012

- Draft NUREG report, "Development of a Performance Testing Protocol for Nuclear Power Plant Flood Penetration Seals," in progress

- Reports prepared by NRC contractors, including Fire Risk Management, Inc. and Center for Nuclear Waste Regulatory Analyses

- Materials Related to Fire Barriers or Fire Tests

- NUREG/CR-0152, "Development and Verification of Fire Tests for Cable Systems and System Components," 1978

- NUREG/CR-2377, "Tests and Criteria for Fire Protection of Cable Penetrations," 1981

- NUREG-1552, "Fire Barrier Penetration Seals in Nuclear Power Plants," 1996

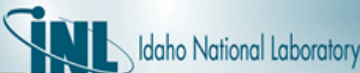

\section{Literature Review (cont.)}

\section{List of Reviewed Materials (cont.)}

\section{ACE Engineering Research and Development Center (ERDC)}

- ERDC TR-07-3, "Flood-Fighting Structures Demonstration and Evaluation Program: Laboratory and Field Testing in Vicksburg, Mississippi," 2007

- ERDC/CHL TR-15-3, "Technical Basis for Flood Protection at Nuclear Power Plants," 2015

\section{OECD NEA}

- NEA draft report, "Concepts and Terminology for Protecting Nuclear Installations from Flood Hazards," in progress

\section{NEI}

- NEI 12-07, Rev. 0-A, "Guidelines for Performing Verification Walkdowns of Plant Flood Protection Features," 2012

\section{EPRI}

- Product 3002005423, "Flood Protection Systems Guide," 2015

- Presentation, "External Flood Seal Risk-Ranking Process," 2019 


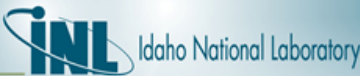

\section{Literature Review (cont.)}

\section{List of Reviewed Materials (cont.)}

\section{Licensee Walkdown Reports}

- Flooding walkdown reports of a reference NPP, 2013-2014

\section{INL \& ISU}

- Pope et al., "Light Water Reactor Sustainability Program, Nuclear Power Plant Mechanical Component Flooding Fragility Experiments Status (INL/EXT-1742728)," 2017

- Wells et al., "Non-watertight door performance experiments and analysis under flooding scenarios," Results in Engineering, 2019

\section{Others (ongoing)}

- NPP decommissioning info, vendor info, and scientific publications

\section{Outputs of Literature Review}

Generic categorization of flood barriers in NPPs

Plant-specific flood barrier types and performances (to be presented in part II)

Existing and potential flood barrier testing facilities

Examples of previous flood barrier tests (to be presented in part III)

Insights for future flood barrier testing strategy development

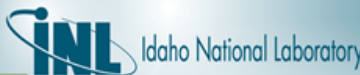

\section{Plant-Specific Flood Barrier Types and Performances}

\section{Reviewed Flooding Walkdown Reports of a Reference Plant}

- Most of inspected protection features in the plant are flood barriers

$\square$ Most of inspected flood barriers are incorporated into the plant

\begin{tabular}{l|l|l|l|}
\hline Feature Type & Classified as Barrier & Barrier Type & Percentage \\
\hline Seal & Yes & Incorporated & $79.11 \%$ \\
\hline Structure & Yes & Incorporated & $7.75 \%$ \\
\hline Drain & No & n/a & $7.51 \%$ \\
\hline Scupper & No & n/a & $3.76 \%$ \\
\hline Dike & Yes & Exterior & $0.94 \%$ \\
\hline Sump & No & n/a & $0.70 \%$ \\
\hline Monitor Well & No & n/a & $0.23 \%$ \\
\hline Percentage of Barrier-Type Features & & $87.79 \%$ \\
\hline \multicolumn{2}{l}{ Percentage of Non-Barrier-Type Features } & $12.21 \%$ \\
\hline
\end{tabular}




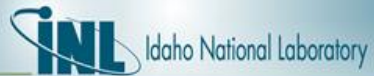

\section{Plant-Specific Flood Barrier Types and Performances (cont.)}

\section{Flood Barrier Types in the Reference Plant}

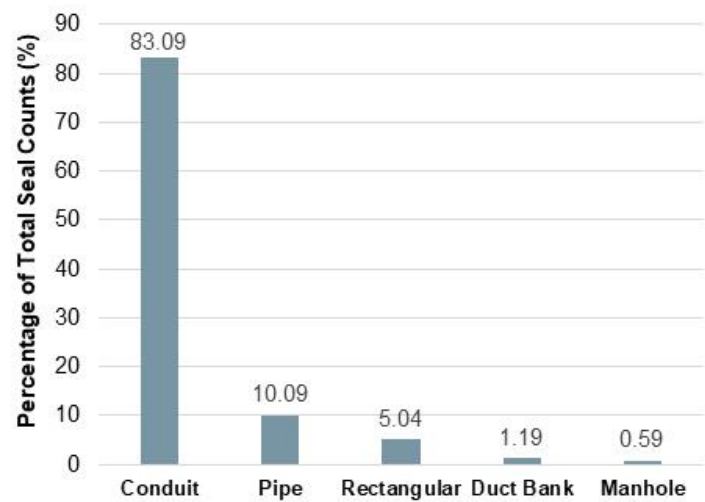

Penetration Seals

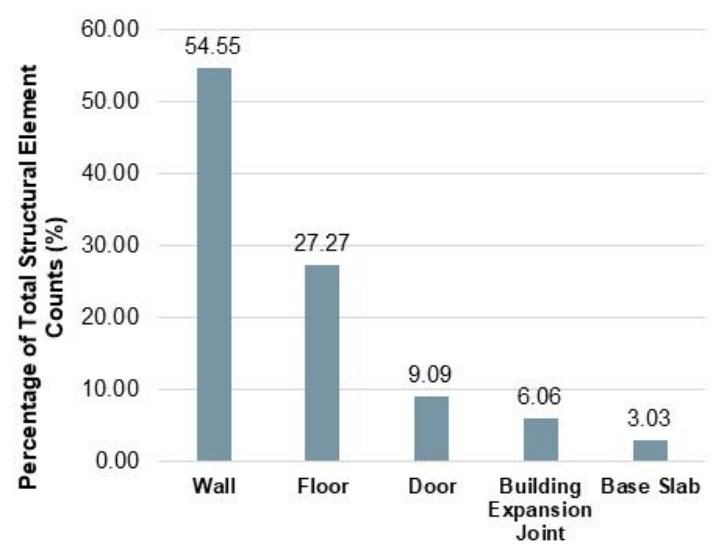

Structural Elements

II. Plant-Specific Flood Barrier Types and Performances (cont.)

Flood Barrier Performances in the Reference Plant

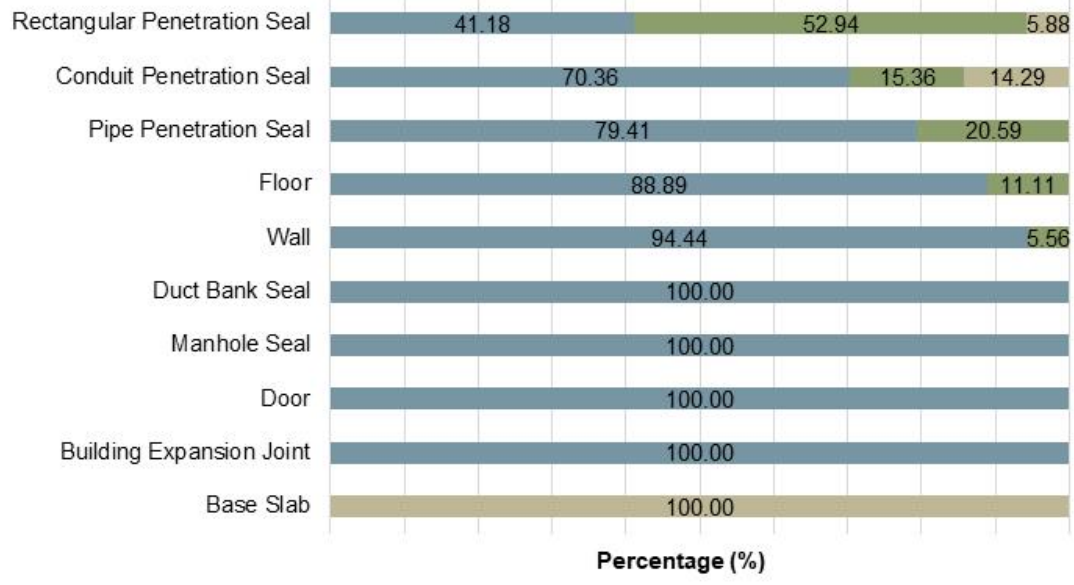

mImmediately Judged as Acceptable $=$ Not Immediately Judged as Acceptable $=$ Inaccessible 


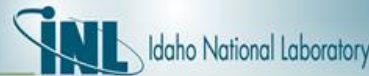

II. Plant-Specific Flood Barrier Types and Performances (cont.)

\section{Flood Barrier Performances in the Reference Plant (cont.)}

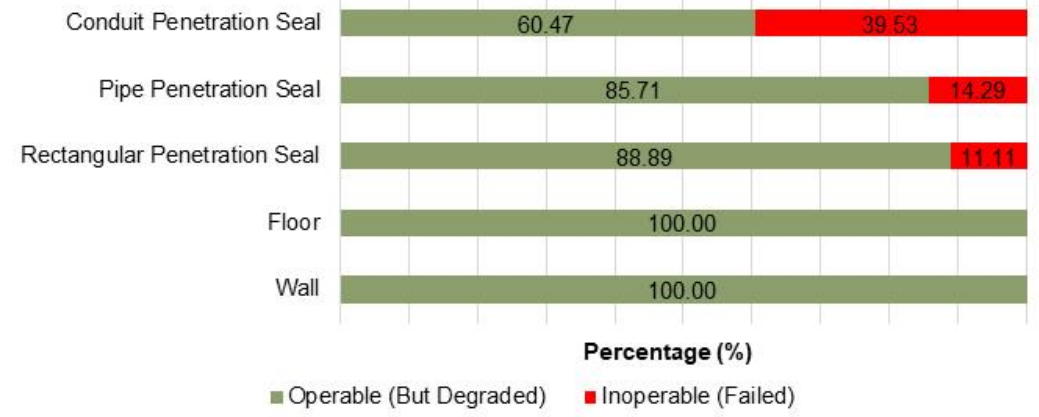

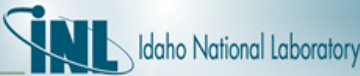

II. Plant-Specific Flood Barrier Types and Performances (cont.)

\section{Degraded Flood Barriers in the Reference Plant}

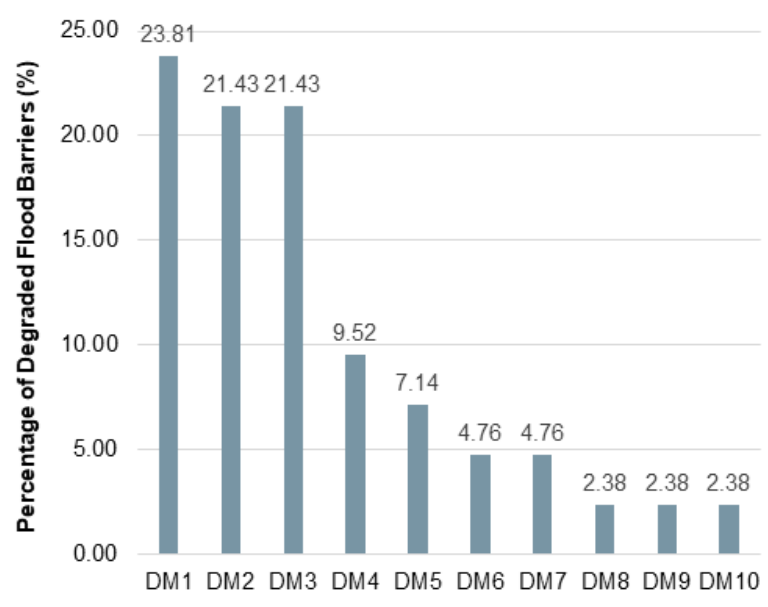

\begin{tabular}{|c|c|}
\hline No. & Degradation Mode (DM) \\
\hline DM1 & $\begin{array}{l}\text { Corrosion on penetration and signs of water } \\
\text { seepage on wall. }\end{array}$ \\
\hline DM2 & $\begin{array}{l}\text { Staining on wall below penetration or at } \\
\text { construction joints of penetration and } \\
\text { immediately below. }\end{array}$ \\
\hline DM3 & No seal could be observed for this penetration. \\
\hline DM4 & Staining on wall and corrosion on penetration. \\
\hline DM5 & $\begin{array}{l}\text { Extensive corrosion on penetration sleeves and } \\
\text { stalactite growth underneath the penetration and } \\
\text { cap. }\end{array}$ \\
\hline DM6 & $\begin{array}{l}\text { Cracks greater than } 0.04 \text { " wide in the wall/floor } \\
\text { slab. }\end{array}$ \\
\hline DM7 & $\begin{array}{l}\text { Penetration covered by a catch and inaccessible. } \\
\text { Staining on the wall below the catch. }\end{array}$ \\
\hline DM8 & $\begin{array}{l}\text { Staining on penetration and signs of water } \\
\text { seepage on wall. }\end{array}$ \\
\hline DM9 & $\begin{array}{l}\text { Cracks greater than } 0.04 \text { " wide in the grout } \\
\text { sealing penetration and slight staining below } \\
\text { pipes. }\end{array}$ \\
\hline DM10 & $\begin{array}{l}\text { Due to an obstructed view, an internal seal for } \\
\text { this pipe sleeve could not be verified. }\end{array}$ \\
\hline
\end{tabular}




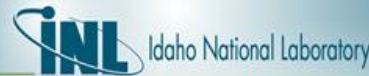

II. Plant-Specific Flood Barrier Types and Performances (cont.)

\section{Failed Flood Barriers in the Reference Plant}
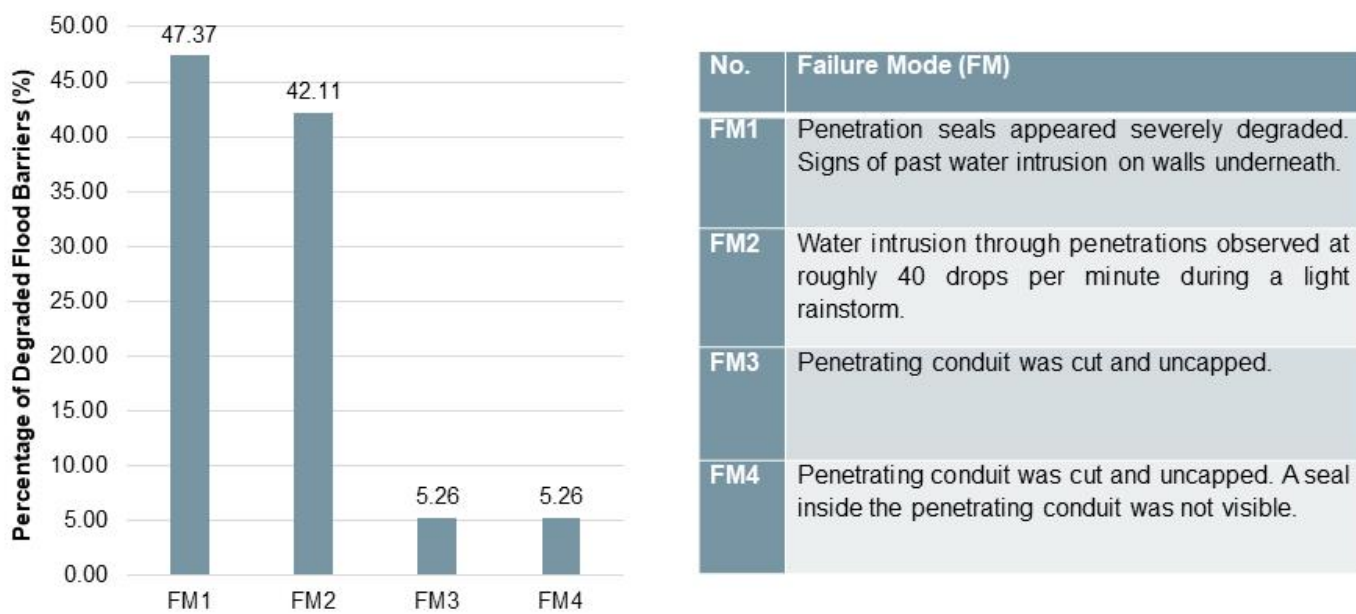

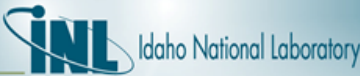

\section{Plant-Specific Flood Barrier Types and Performances (cont.}

\section{Performance Metrics of Flood Barriers in the Reference Plant}

- Could possibly act as an input for development of flood barrier testing strategy

- Failure probability could be one of multiple factors to be considered for test prioritization

\begin{tabular}{|l|l|l|l|}
\hline \multirow{2}{*}{ Flood Barrier } & Probability & \multicolumn{2}{l|}{} \\
\cline { 2 - 4 } & Success & Degradation & Failure \\
\hline Conduit Penetration Seal & 0.82 & 0.11 & 0.07 \\
\hline Rectangular Penetration Seal & 0.44 & 0.50 & 0.06 \\
\hline Pipe Penetration Seal & 0.79 & 0.18 & 0.03 \\
\hline Floor & 0.89 & 0.11 & 0.00 \\
\hline Wall & 0.94 & 0.06 & 0.00 \\
\hline Building Expansion Joint & 1.00 & 0.00 & 0.00 \\
\hline Door & 1.00 & 0.00 & 0.00 \\
\hline Manhole Seal & 1.00 & 0.00 & 0.00 \\
\hline Duct Bank Seal & 1.00 & 0.00 & 0.00
\end{tabular}




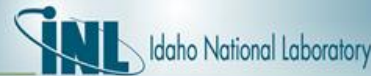

\section{Examples of Previous Flood Barrier Tests}

\section{Test 1 - Penetration Seals, Ex-Situ}

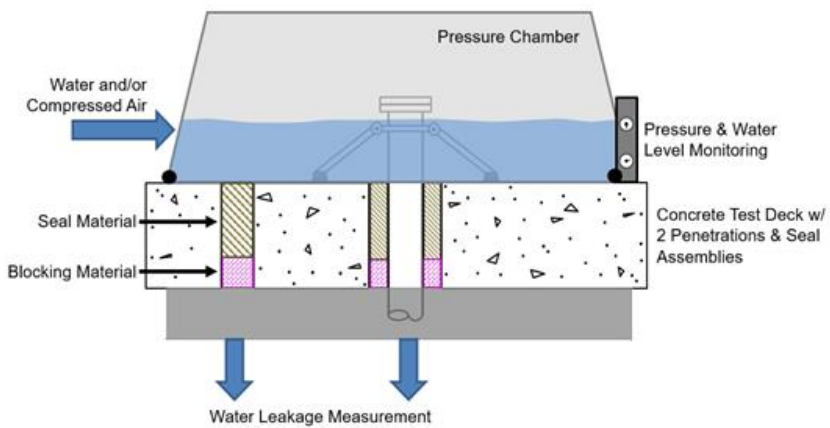

Framatome Laboratory Flood Testing Facility (Lynchburg, VA)

\begin{tabular}{|c|c|}
\hline Flood Barrier Type & Penetration seals \\
\hline Testing Location & Ex-situ \\
\hline Facility Type & $\begin{array}{l}\text { Test deck with pressure } \\
\text { chamber }\end{array}$ \\
\hline Testing Type & Destructive \\
\hline Included Tests & Hydrostatic, hydrodynamic \\
\hline Test Variables & $\begin{array}{l}\text { Water pressure, duration of } \\
\text { applied pressure, rate of } \\
\text { pressure change }\end{array}$ \\
\hline Test Measurements & $\begin{array}{l}\text { Test chamber pressure, water } \\
\text { temperature, water volumetric } \\
\text { flow rates from individual seals }\end{array}$ \\
\hline Test Termination & $\begin{array}{l}\text { Until maximum test duration } \\
\text { was exceeded, or seal failure } \\
\text { occurred }\end{array}$ \\
\hline $\begin{array}{l}\text { Test Outputs } \\
\text { (Numerical) }\end{array}$ & $\begin{array}{l}\text { Test duration, maximum water } \\
\text { pressure, pressure vs. time } \\
\text { graphs, leakage flow rates vs. } \\
\text { time graphs }\end{array}$ \\
\hline
\end{tabular}

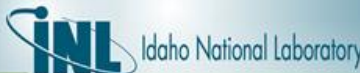

\section{Examples of Previous Flood Barrier Tests (cont.)}

\section{Test 2 - Non-watertight Doors, Ex-Situ}

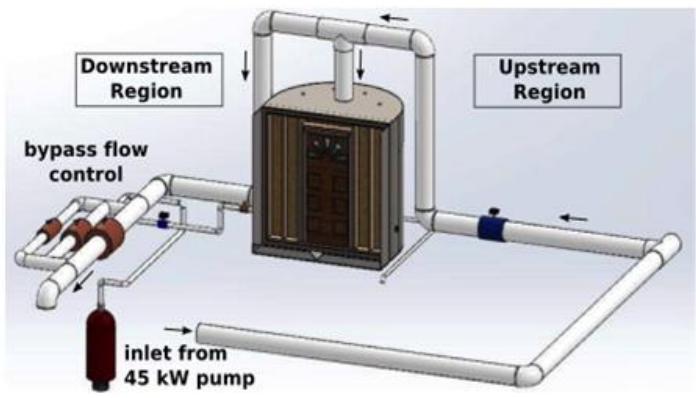

Idaho State University Flood Testing Facility (Pocatello, ID)

\begin{tabular}{|c|c|}
\hline Flood Barrier Type & Doors \\
\hline Testing Location & Ex-situ \\
\hline Facility Type & Tank \\
\hline Testing Type & Destructive \\
\hline Included Tests & Hydrostatic, hydrodynamic \\
\hline Test Variables & Tank filling rate \\
\hline Test Measurements & $\begin{array}{l}\text { Flow rates into the tank, tank } \\
\text { water depth, water } \\
\text { temperature, small leakage } \\
\text { rates, pressures for simulated } \\
\text { hydrostatic head }\end{array}$ \\
\hline Test Termination & $\begin{array}{l}\text { Until door failure, the water } \\
\text { leakage rate equalizing, or } \\
\text { exceeding the filling rate }\end{array}$ \\
\hline $\begin{array}{l}\text { Test Outputs } \\
\text { (Numerical) }\end{array}$ & $\begin{array}{l}\text { Time to failure, failure water } \\
\text { depth, water depth vs. time } \\
\text { graphs }\end{array}$ \\
\hline
\end{tabular}




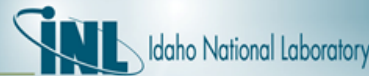

\section{Examples of Previous Flood Barrier Tests (cont.)}

\section{Tests 3 \& 4 - Temporary Flood Barriers, Ex-Situ}

$\square$ Test Sample

- ACE sandbag barrier

- Three commercial barriers

\begin{tabular}{|c|c|c|}
\hline & Test 3 & Test 4 \\
\hline Flood Barrier Type & Temporary barriers & Temporary barriers \\
\hline Testing Location & Ex-situ & Ex-situ \\
\hline Facility Type & Natural site & Research basin \\
\hline Testing Type & Destructive & Destructive \\
\hline Included Tests & Hydrostatic, hydrodynamic & $\begin{array}{l}\text { Hydrostatic, hydrodynamic, overtopping, debris } \\
\text { impact }\end{array}$ \\
\hline Test Variables & Natural flooding & Water level, wave size, wave duration, debris size \\
\hline Test Measurements & $\begin{array}{l}\text { Water levels in seepage collection pits, time } \\
\text { history of construction/testing/removal of tested } \\
\text { barriers, barrier dimensions }\end{array}$ & $\begin{array}{l}\text { Water levels in seepage collection pits, time } \\
\text { history of construction/testing/removal of tested } \\
\text { barriers, barrier dimensions }\end{array}$ \\
\hline Test Termination & $\begin{array}{l}\text { Until a barrier was overtopped by water flowing } \\
\text { freely over the barrier and exceeding pump } \\
\text { capacity on the protected side }\end{array}$ & $\begin{array}{l}\text { Until maximum test duration was exceeded or } \\
\text { barrier failure occurred }\end{array}$ \\
\hline Test Outputs (Numerical) & $\begin{array}{l}\text { Seepage flow rates, seepage rate vs. wetted } \\
\text { perimeter area graphs, seepage rate vs. stage of } \\
\text { the river graphs, operational concerns (e.g., } \\
\text { ease of construction, barrier durability and } \\
\text { reusability) }\end{array}$ & $\begin{array}{l}\text { Seepage flow rates, barrier displacements, } \\
\text { seepage per linear foot vs. time graphs, seepage } \\
\text { \& overtopping vs. time graphs, operational } \\
\text { concerns (e.g., ease of construction, barrier } \\
\text { durability and reusability) }\end{array}$ \\
\hline
\end{tabular}

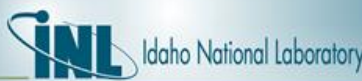

\section{Examples of Previous Flood Barrier Tests (cont.)}

\section{Summary}

Tested flood barriers included:

- Permanent barriers

- Temporary barriers

All the tests were ex-situ

All the tests were destructive

All the tested flood barriers were new without aging or degradation 


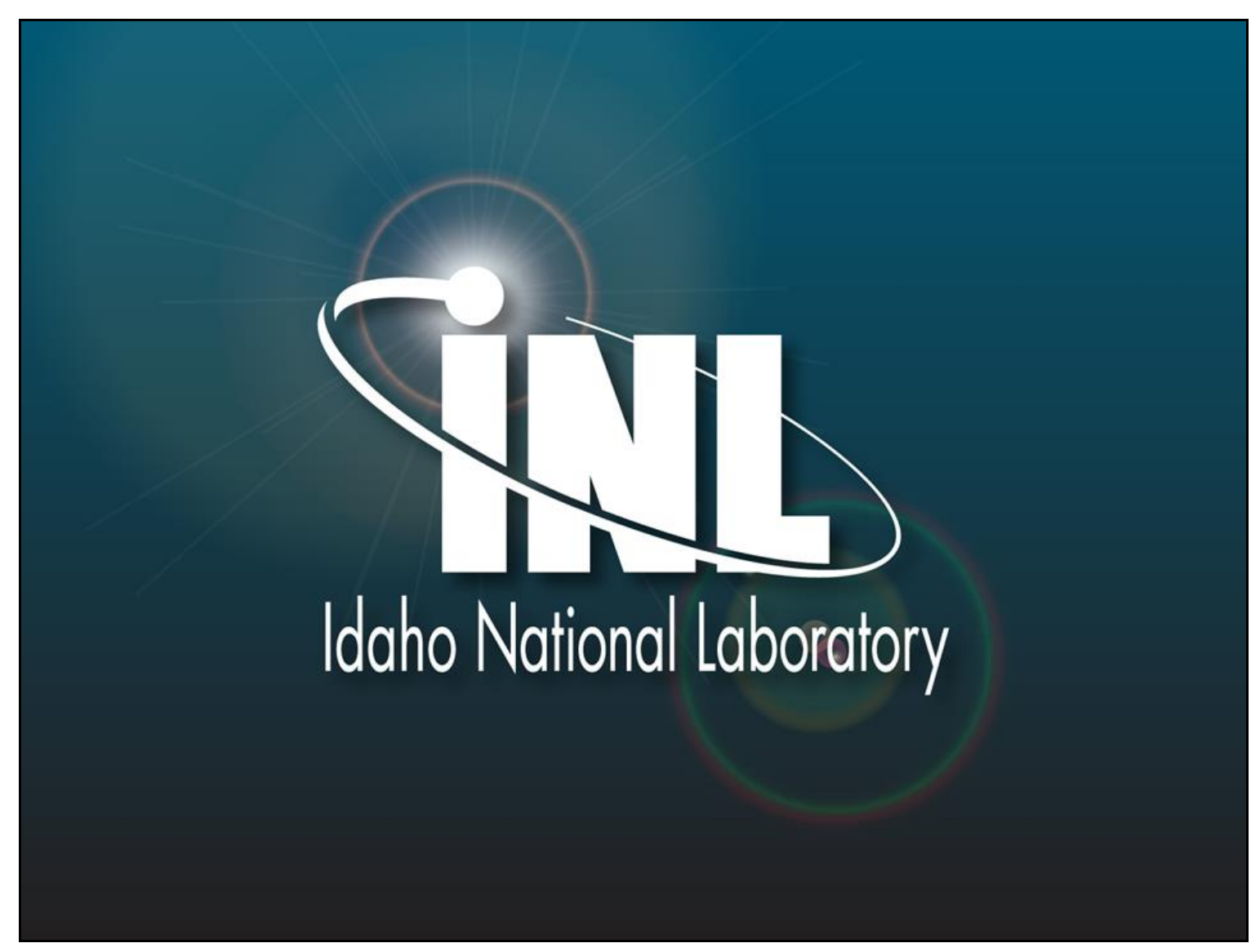

\subsubsection{Questions and Answers}

Question: How would you determine if a flood barrier is "acceptable (Slide 9)"?

Answer: In the flooding walkdown at the reference plant, acceptability of a flood barrier was determined by comparing results of visual inspection conducted during walkdown to acceptance criteria as defined in NEI 12-07, Revision 0-A [1] and plant-developed supplemental walkdown inspection guidance. Section 6 of NEI 12-07, Revision 0-A defines "acceptance" as:

"Flood protection features are considered acceptable if no conditions adverse to quality were identified during walkdowns, verification activities, or program reviews as determined by the licensee's Corrective Action Program. Conditions adverse to quality are those that prevent the flood protection feature from performing its credited function during a design basis external flooding event and are 'deficiencies. '” [1]

Question: What were the acceptance criteria used for base slab (Slide 9)?

Answer: Base slab was deemed inaccessible during walkdown. No information of acceptance criteria of base slab was found in the walkdown report.

Question: Is FM Approval Standard FM 2510 [2] for flood mitigation equipment included in the review? Answer: Not yet, but we will include this standard in our literature review. 
2.5 Flood Rated Penetration Seal Research Overview

Presented by W. Mark Cummings (Fisher Engineering, Inc.)

\title{
2.5.1 Presentation
}

\section{FLOOD RATED PENETRATION SEAL RESEARCH OVERVIEW}

\author{
W. Mark Cummings, P.E.
}

Fisher Engineering, Inc. 
(4) FISHER Flood Penetration Seal Performance Evaluation

\section{NRC PROJECT TITLE: Flood Penetration Seal Performance at NPPs}

Project Team: Fire Risk Management, Inc. (now Fisher Eng.) Nuvia US

\section{Project Overview:}

Project Objective: To establish Testing Standards and Protocols to evaluate the effectiveness and performance of seals for penetrations in flood rated barriers at NPPs.

\section{Project Tasks:}

Task 1: Development of Testing Standards, Acceptance Criteria, and Protocols

Task 1.1: Identify and describe the various typical seal materials for FPSs used at NPPs

Task 1.2: Develop standard testing procedures, acceptance criteria and protocols for testing effectiveness and performance of FPSs.

Task 2: Testing of Selected Flood Penetration Seal Types and Designs

- Designed to "test the test protocol"

- Use observations to determine if mods to Test Protocol are warranted

\section{(4. FISHER Flood Penetration Seal Performance Evaluation}

\section{TASK 1.1 OVERVIEW}

Researched publicly-available information regarding installed Flood-rated Penetration Seals

- ADAMS database

- NPP responses to NRC 50.54 Letter (54)

- NRC Audit Reports

- LERs, NUREGs, INs. IRs (relevant info noted in 28/-/15/13)

Wide variety of seal assemblies and materials noted

- Concrete, Mortar, Grout

- Mechanical seals (such as boot or link)

- Silicone foams (high \& low densities)

- Epoxies \& Elastomers

- Urethane

- Caulking

Combination of "fill" materials with exterior "damming" materials applied (waterproofing) 


\section{(4) FISHER Flood Penetration Seal Performance Evaluation}

\section{TASK 1.1 OVERVIEW (Cont'd)}

Wide range of penetration configurations and types of penetrants

- Rectangular \& Circular

- Sleeved and Core Bore

- Single \& Multiple Penetrants and "Blanks"

- Pipes, Cables, Conduit, etc.

- Varying sizes / diameters

Both interior and exterior applications

FPS Assessments

" "Formed in place" seals (foams, elastomers) appear to exhibit greatest variability in performance

- Materials / Products (formulations) vary between Manufacturers

Summary Report Developed: "“Flood Penetration Seal Assemblies at Existing Nuclear Power Plants" (08/2016)

\section{(4. FISHER Flood Penetration Seal Performance Evaluation}

\section{TASK 1.2 OVERVIEW}

Review of NUVIA Flood Test Apparatus \& Procedures

- NUVIA is only entity currently testing FPSs; using standard procedures/protocols

Review of UL 1479 - Fire Tests of Through-Penetration Firestops

- Section 6A-Water Leakage Test (W rating)

Review of FM Approval Standard for Flood Abatement Equipment

- Does not address "penetrations" in flood barriers; primarily the barriers themselves, including dikes

- Does provide some input regarding "impact" resistance

Review of ASTM E814 - Standard Test Method for Fire Tests of Penetration Firestop Systems

" Used as a primary "template" for formatting Flood Test Procedure

- Industry familiarity with formatting 


\section{(4) FISHER Flood Penetration Seal Performance Evaluation}

\section{TASK 1.2 OVERVIEW (Cont'd)}

Development of draft Protocol complete - ready for use in Phase II

- Provided "guidance" and standardized methodology for testing flood-rated penetration seals

Test apparatus design; including data acquisition

Performance-based approach to metrics (no specific pass/fail criteria)

- Manufacturers will need to specify limitations of their products

- Use Task 2 testing to assess Protocol flexibility with the p-based approach

- NRC Issued Draft for public review/comment 02/2018 - "Draft Methodology for Testing and Evaluating the Performance of Flood Penetration Seals"

\section{(4) FISHER Flood Penetration Seal Performance Evaluation}

\section{TASK 2 OVERVIEW}

Updated Draft Test Methodology

- Updates based on public comment

- Final draft developed for use during Task 2 testing series; 06/2018

Development of Test Plan

- Selection of candidate FPSs; types and numbers to be tested

- Final design for Test Decks (Installed Penetrations \& Seal Assemblies)

- Location for testing (Framatome Lab in Lynchburg, VA)

- Inclusive of Test Matrix

Range of seal assemblies/materials

Greater emphasis on "formed in place" (including configurations noted during Task 1)

Specific penetrations assigned to participating Mfgrs

" Final Test Plan submitted to NRC 07/2018; "Test Plan for Flood-rated Penetration Seal Performance Testing"

Test Objective(s)

" Exercise \& evaluate Flood Test Procedure ("test the test")

- Research/Evaluation of specific FPS assemblies/materials noted as installed at NPPs 


\section{(4. FISHER Flood Penetration Seal Performance Evaluation}

\section{TASK 2 - Test Series}

Candidate Test Decks

- General design/configuration predicated on Framatome Test Apparatus

" 12 " concrete "slabs"

- 5 Sample Decks included in Test Series

- Variety of circular \& rectangular/square penetrations

- Sleeved \& core drilled

" "blanks" \& variety of penetrants: pipe (PVC), cable, cable \& cable trays, conduit

" Low \& High density foam \& silicone materials

- Mechanical seals; boot \& link types

- Restrained \& unrestrained penetrants

" Penetrants sealed to prevent leakage "through" penetrating item

\section{(4. FISHER Flood Penetration Seal Performance Evaluation}

\section{TASK 2 - Test Series}

Candidate Test Decks - Pre-test Preparation
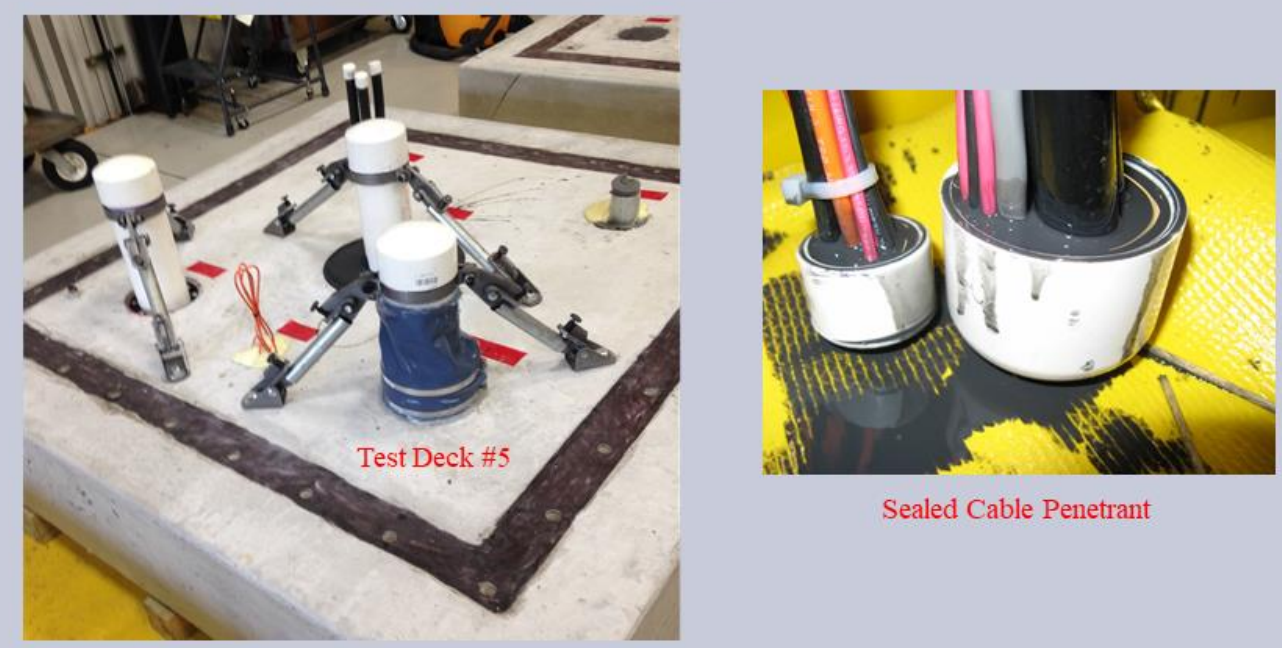

Sealed Cable Penetrant 


\section{(4) FISHER Flood Penetration Seal Performance Evaluation}

\section{TASK 2 - Test Series}

Candidate Test Decks - Pre-test Preparation

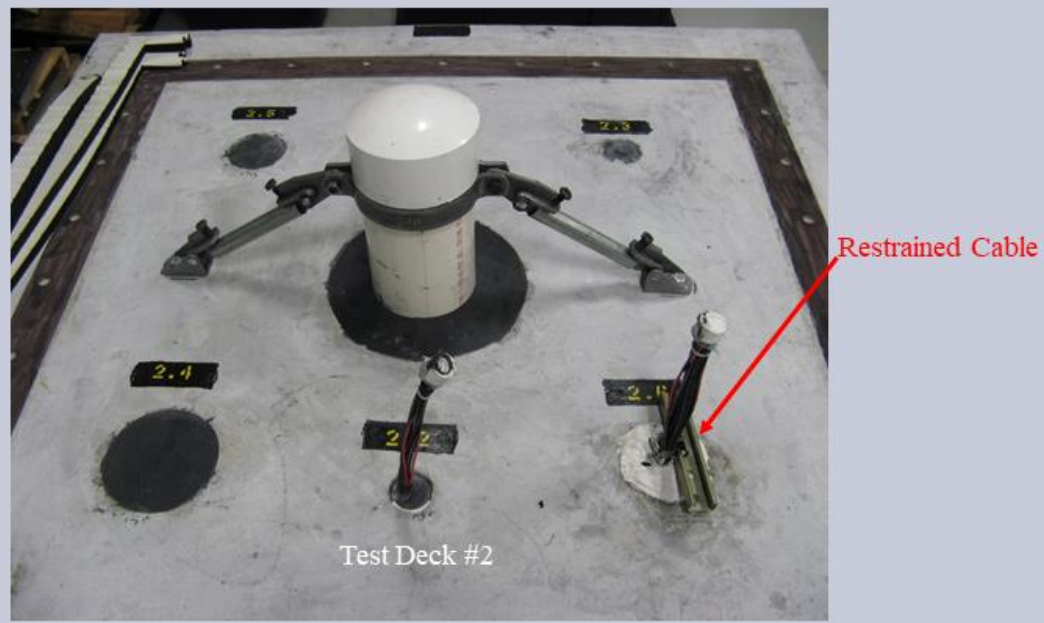

\section{(1) FISHER Flood Penetration Seal Performance Evaluation}

\section{TASK 2 - Test Series}

Candidate Test Decks - Pre-test Preparation

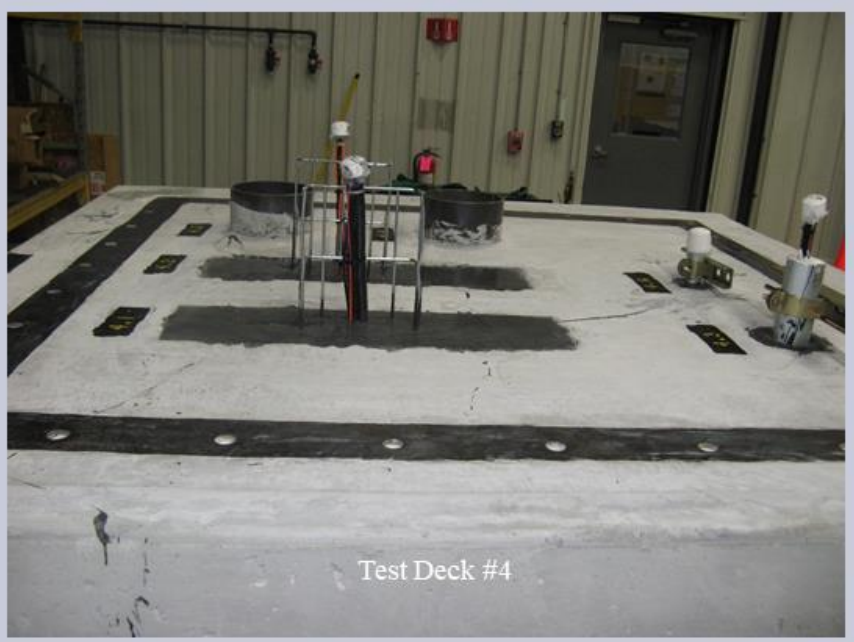




\section{(4) FISHER Flood Penetration Seal Performance Evaluation}

\section{TASK 2 RESULTS}

- Candidate Test Decks - Post-test Results

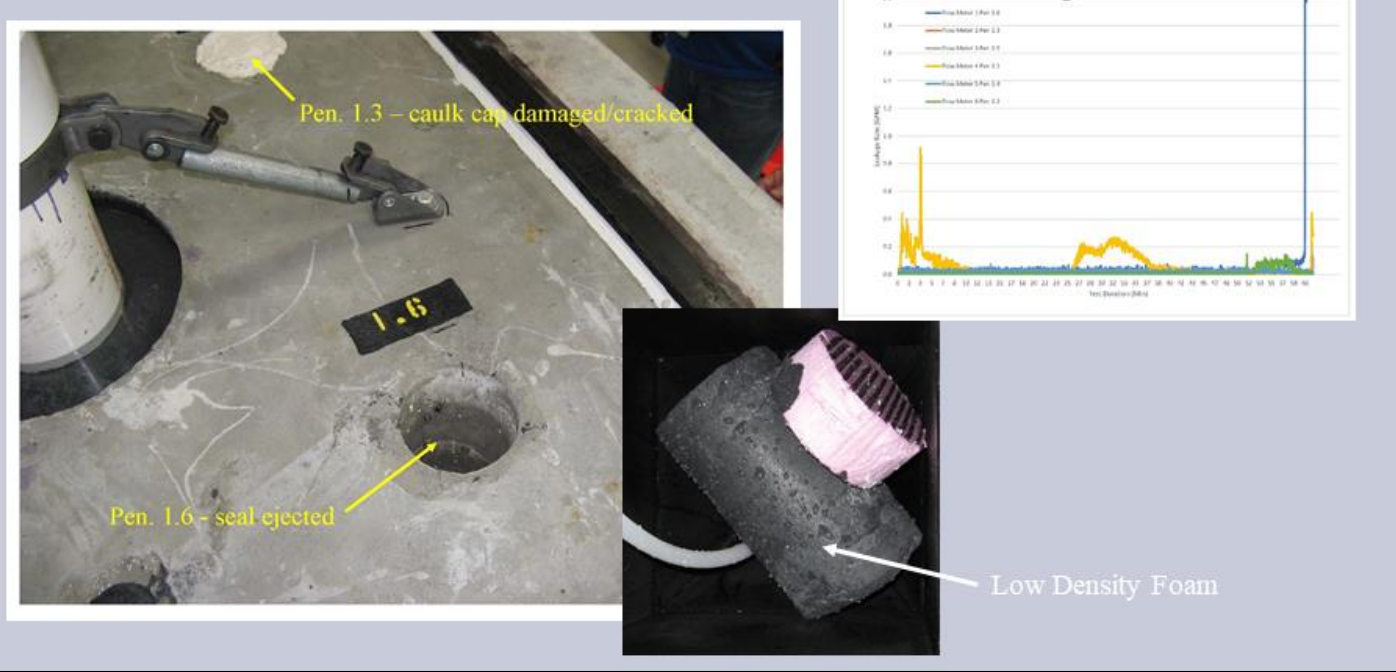

\section{(\) FISHER Flood Penetration Seal Performance Evaluation}

\section{TASK 2 RESULTS}

- Candidate Test Decks - Post-test Results

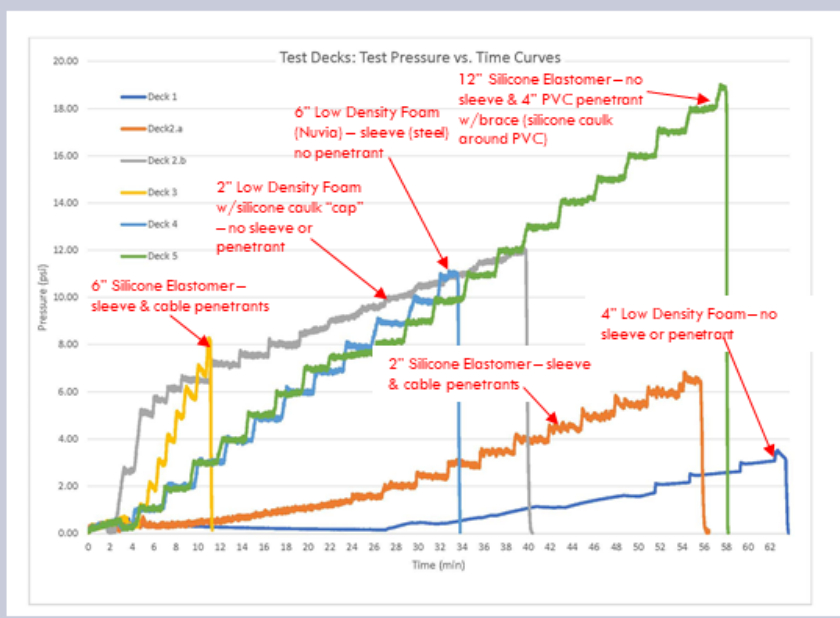




\section{(4.) FISHER Flood Penetration Seal Performance Evaluation}

\section{TASK 2 RESULTS}

- Candidate Test Decks - Post-test Results

Lessons Learned

Mechanical Seals performed well (link \& boot seals $\geq 19$ psig)

Performance of low density foam dependent on numerous variables

Number/type of penetrant(s)

Sleeved vs. unsleeved and sleeve material

Small "free area" to circumference ratio (higher density fill ratio)

Silicone elastomer did not adhere well to PVC penetrant or sleeve

Better performance with restrained penetrant(s) (low density foams/high density elastomers)

Test Methodology Appears Adequate and Flexible to Support Seal Performance Data

- Final Task 2 Testing (Summary) Report Submitted

"Flood-Rated Penetration Seal Performance Testing" (09/2018)

\section{(@) FISHER Flood Penetration Seal Performance Evaluation}

\section{PATH FORWARD}

Promulgation of Test Methodology for Industry Use

- Issued via NUREG (NRC action)

Provide guidance to Industry for standardized process for evaluating/quantifying FPS performance

Support NRC oversight requirements

FPS pass/fail criteria will be function of Flood PRA requirements; NPP-specific 
2.6 Flood Barrier Testing Facility - ISU

Presented by Chad L. Pope (ISU)

\subsubsection{Presentation}

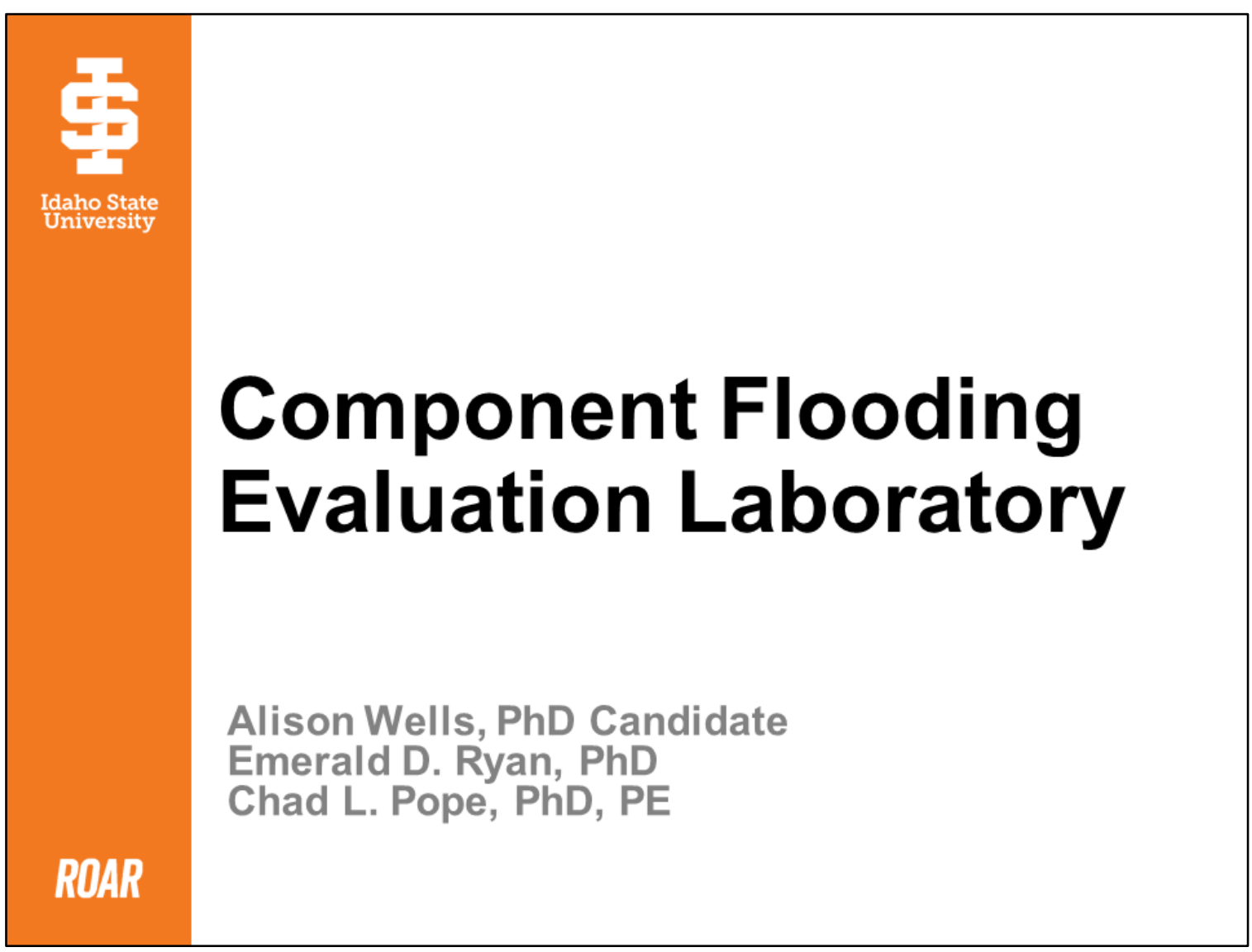




\section{Objective}

Support development of deeper comprehension of nuclear power plant flooding risks through three pathways:

1. Execution of component flooding experiments

2. Comprehensive data analysis and component fragility curve development

3. Integration of component fragility into flooding simulation

\section{Portal Evaluation Tank}

- 2,000-gal tank

- 8,000-gal reservoir

- 4500 gpm pump

- $8 \mathrm{ft} \times 8 \mathrm{ft}$ opening for components
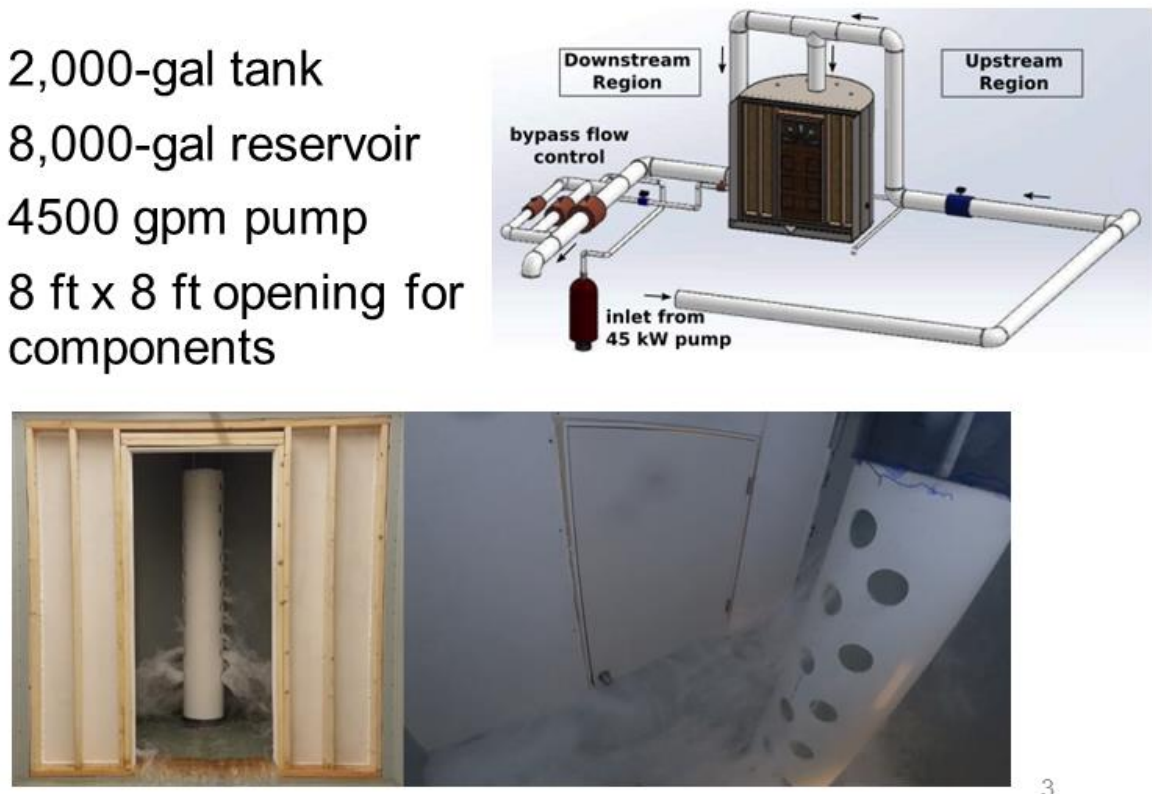


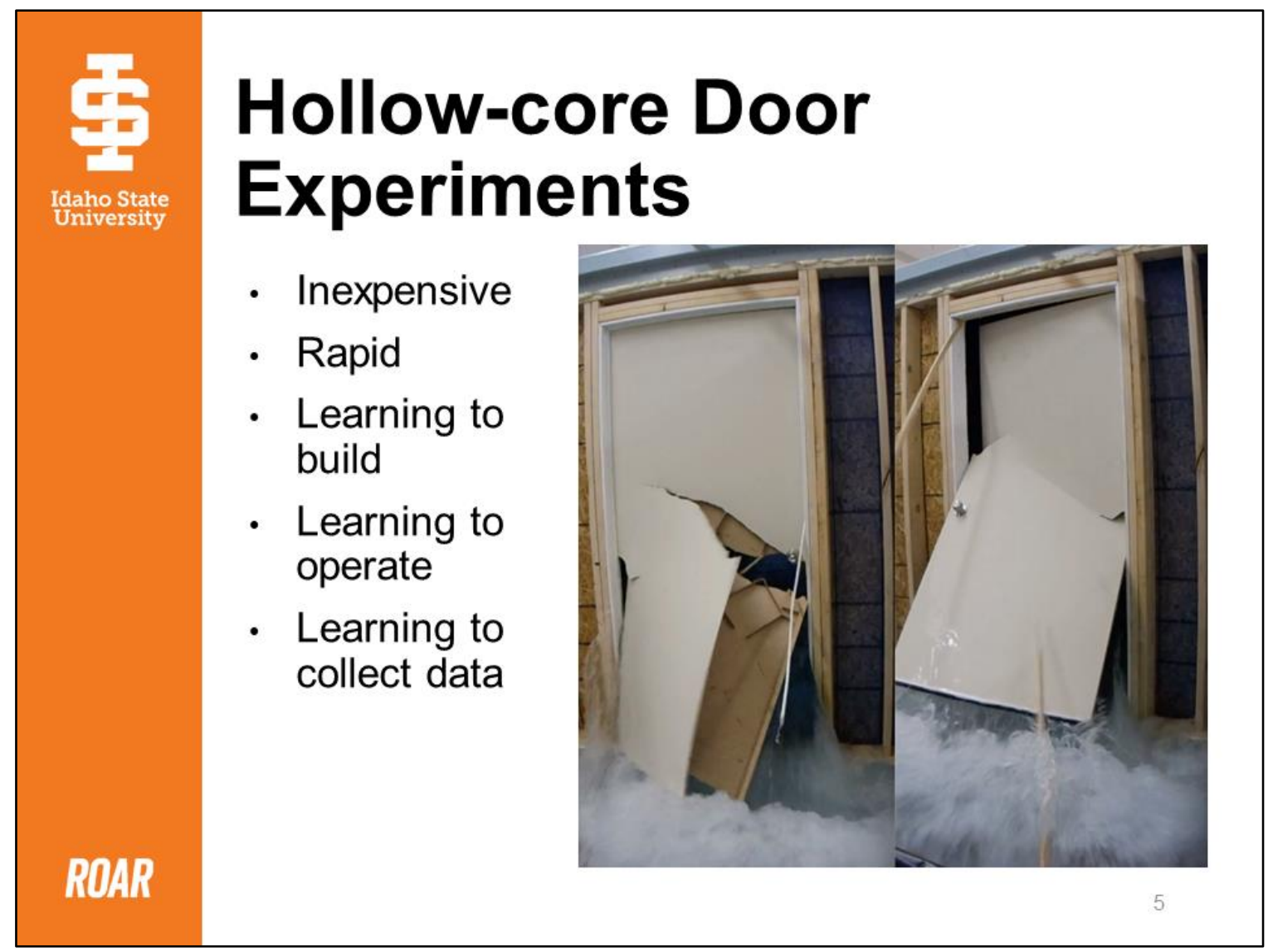

한돈

Idaho State

University

\section{Steel Door Experiments}

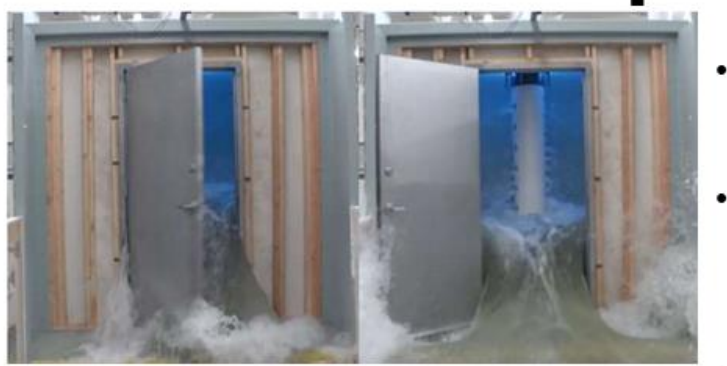

- Representative of industrial setting

- Required strengthened construction

- Outward swinging

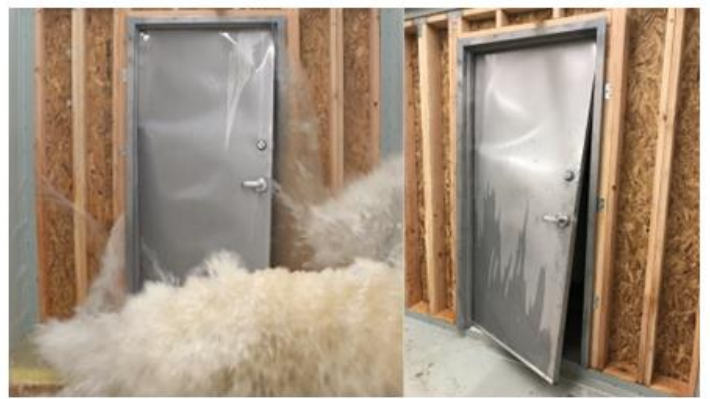

- Inward swinging

- With and without dead-bolt 


\section{Inward Swing Steel Door}

\section{Idaho State U N I V E R S I T Y}

\section{Component Flooding Evaluation Laboratory}

\section{ROAR}

tra

Idaho State

University

ROAR

\section{Fragility Modeling Approach}

- Most fragility modeling has focused on seismic component fragility determination

- Additional observables may be better indicators for the potential of failures

- $X, Y$, and $Z$ parts of the ground motion

- Frequency of the wave

- Age of component

- Anchorages of the component

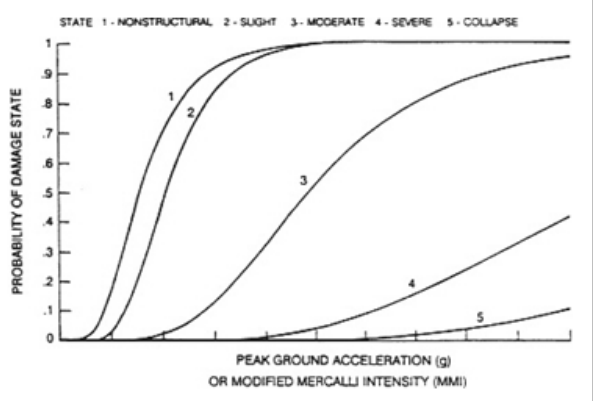

- Specifics of the component type

- Limitations can be avoided by moving to a more flexible, datainformed approach

- Bayesian fragility modeling through experiment-driven regression modeling 


\section{Model Development}

Idaho State

University
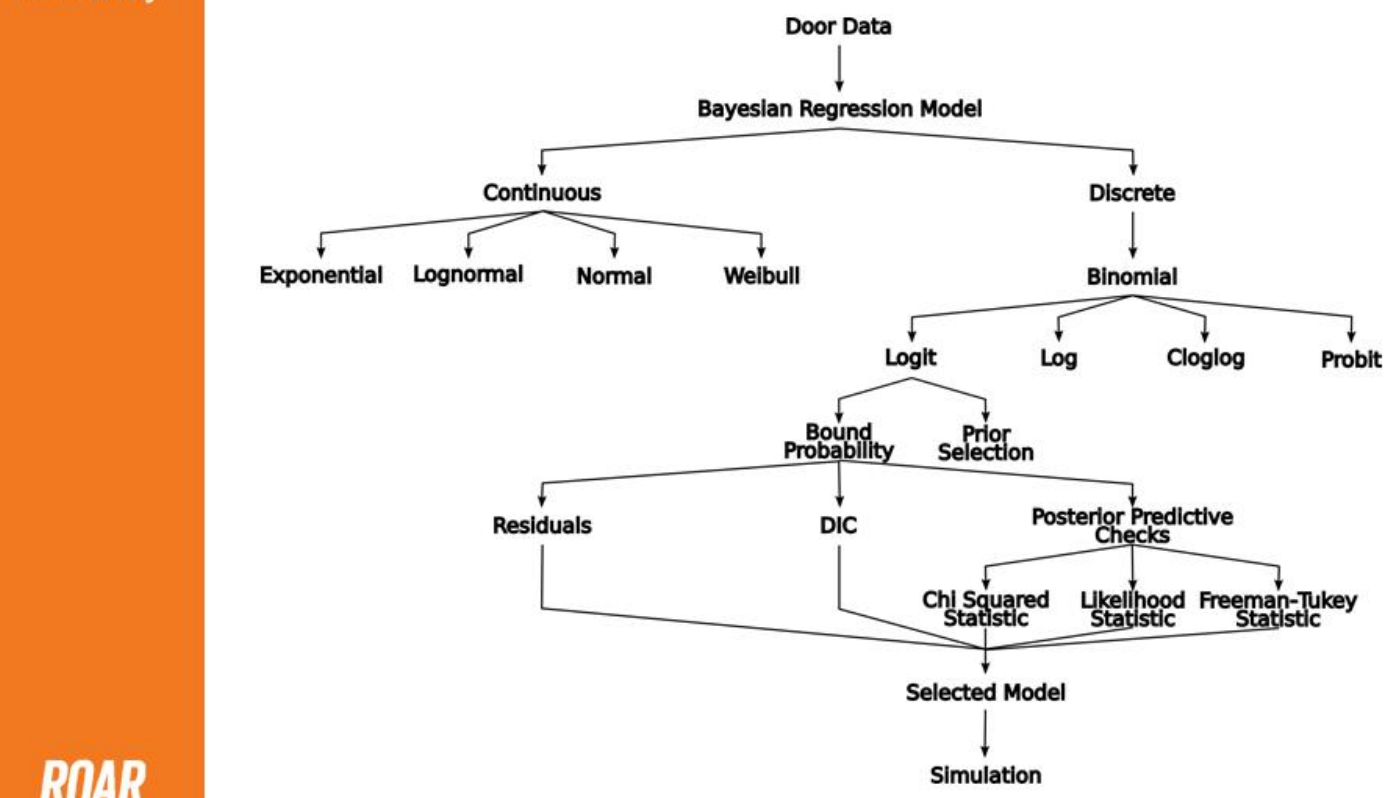

ROAR

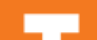

ar

re

ra

Idaho State

University

\section{Bayesian Inference}

- Need a model that represents the failure of a component during a flooding event

- Binomial model

- Key variable is probability of failure, $p$

- Determine what observable phenomena drive failure

- Turn the parameter $p$ into its own regression model

- $p$ is possibly a function of the water depth, flow rate, and even temperature model

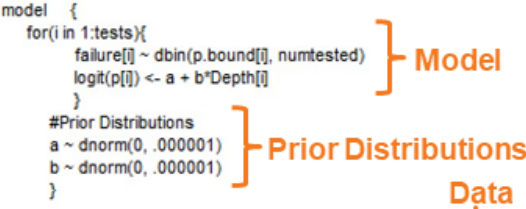




\section{Steel Door Results}

Idaho State

University

\begin{tabular}{|c|c|c|c|}
\hline Parameter & Depth & Flow Rate & Depth \& Flow Rate \\
\hline a (intercept) & -75.68 & -8.51 & -72.5 \\
\hline b (depth coeff.) & 2.05 & na & 1.83 \\
\hline c (flow rate coeff.) & na & 0.01 & 0.007 \\
\hline $\begin{array}{c}\text { sat. deviance } \\
\text { Chi-square } \\
\text { p-value }\end{array}$ & $12.88(10.65,17.43)$ & $14.29(12.07,18.92)$ & $13.31(10.1,18.82)$ \\
\hline $\begin{array}{c}\text { Likelihood ratio } \\
\text { p-value }\end{array}$ & 0.19 & 0.26 & 0.14 \\
\hline $\begin{array}{c}\text { Freeman-Tukey } \\
\text { P-value }\end{array}$ & 0.38 & 0.36 & 0.29 \\
\hline DIC & 0.33 & 0.23 & 0.21 \\
\hline
\end{tabular}

- Posterior estimates can be used with the fragility model to calculate the failure probability for a steel door:

$$
p=\frac{1}{e^{-(-75.68+2.05 D)}+1}
$$

\section{Steel Door Fragility Curve}

Idaho State

University

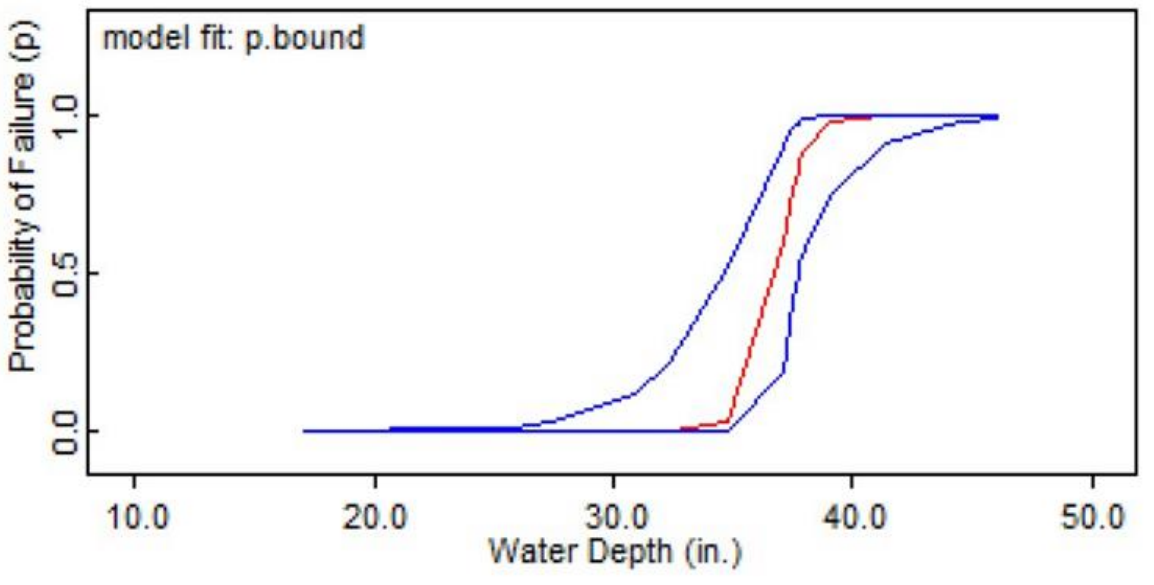




\section{Smoothed Particle Hydrodynamics}

rom

- Particle based, Lagrangian, method - Time stepping scheme

- Interpolation method

- A particle's property depends on the $\quad v_{t+\Delta t}=v_{t}+\Delta t a_{t}$

- particles surrounding

$r_{t+\Delta t}=r_{t}+\Delta t v_{t+\Delta t}$

- Momentum

- Compressibility model

$\frac{d \boldsymbol{v}_{i}}{d t}=-\sum_{j} m_{j}\left(\frac{P_{j}}{\rho_{j}^{2}}+\frac{P_{i}}{\rho_{i}^{2}}+\Pi_{i j}\right) \nabla_{i} W_{i j}+\boldsymbol{g} \quad \boldsymbol{v}_{i}^{*}=\boldsymbol{v}_{i}(t)+\Delta t\left(-\sum_{j} m_{j} \Pi_{i j} \nabla W_{i j}(t)+\boldsymbol{g}\right)$

- Continuity

$\frac{d \rho_{i}}{d t}=\sum_{j} m_{j} v_{i j} \cdot \nabla_{i} W_{i j}$

- Moving particles

$\frac{d \boldsymbol{r}_{i}}{d t}=\boldsymbol{v}_{i}+\frac{1}{2} \sum_{j} \frac{m_{j}}{\rho_{i j}} \boldsymbol{v}_{i j} W_{i j}$

ROAR

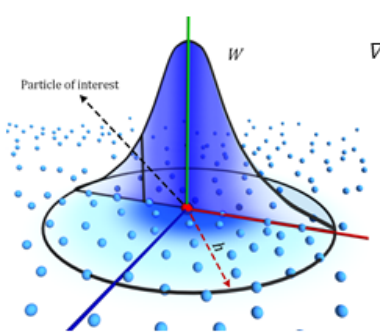

$\nabla^{2} p_{i}(t)=\frac{\rho_{0}-\rho_{i}^{*}}{\Delta t^{2}}$

5

Idaho State

\section{Particle Spacing Selection}

- $0.0625 \mathrm{~m}$ particle spacing

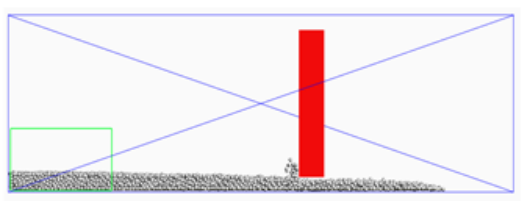

- $0.03125 \mathrm{~m}$ particle spacing

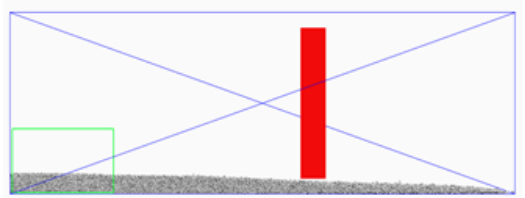




\section{Simulation Overlay}

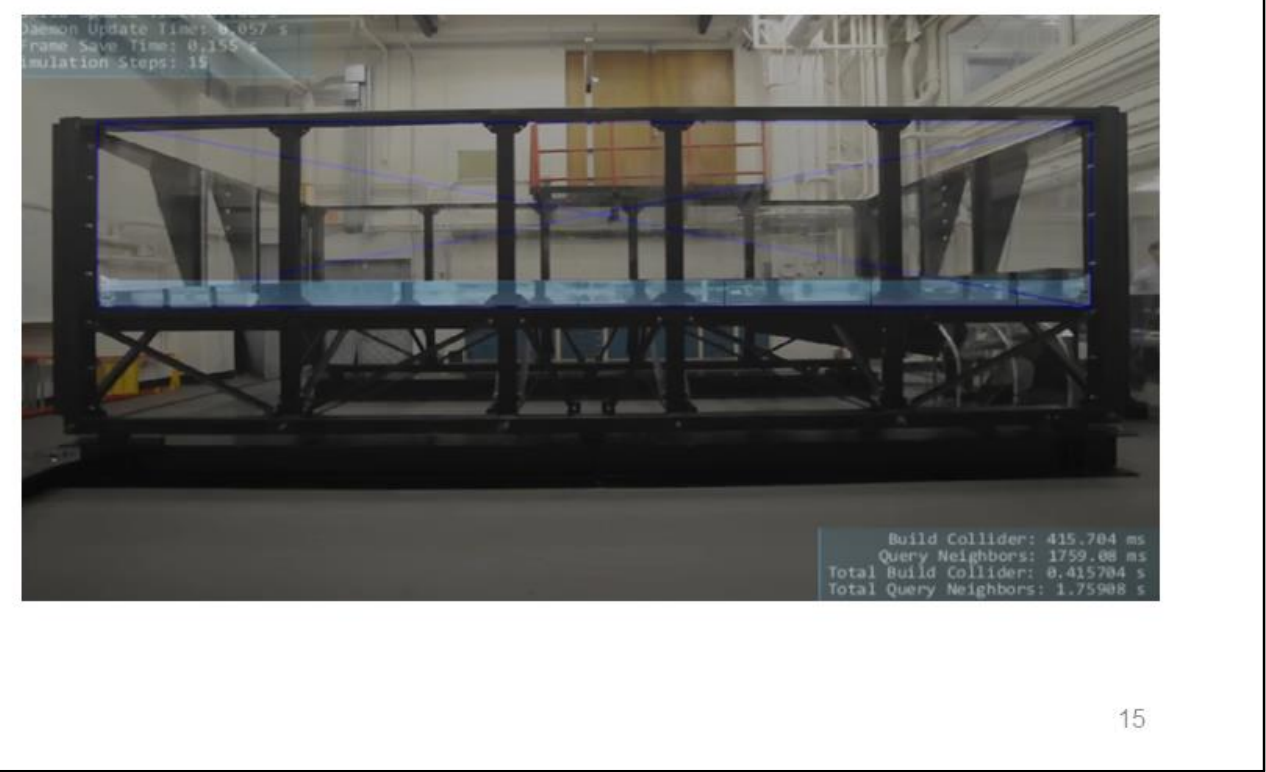

ROAR

\section{Fragility Integration}

Idaho State

- Flooding fragility can improve simulation to realistically model component behavior

- Couple fragility model to Neutrino via Python dynamic expression scripts

ROAR
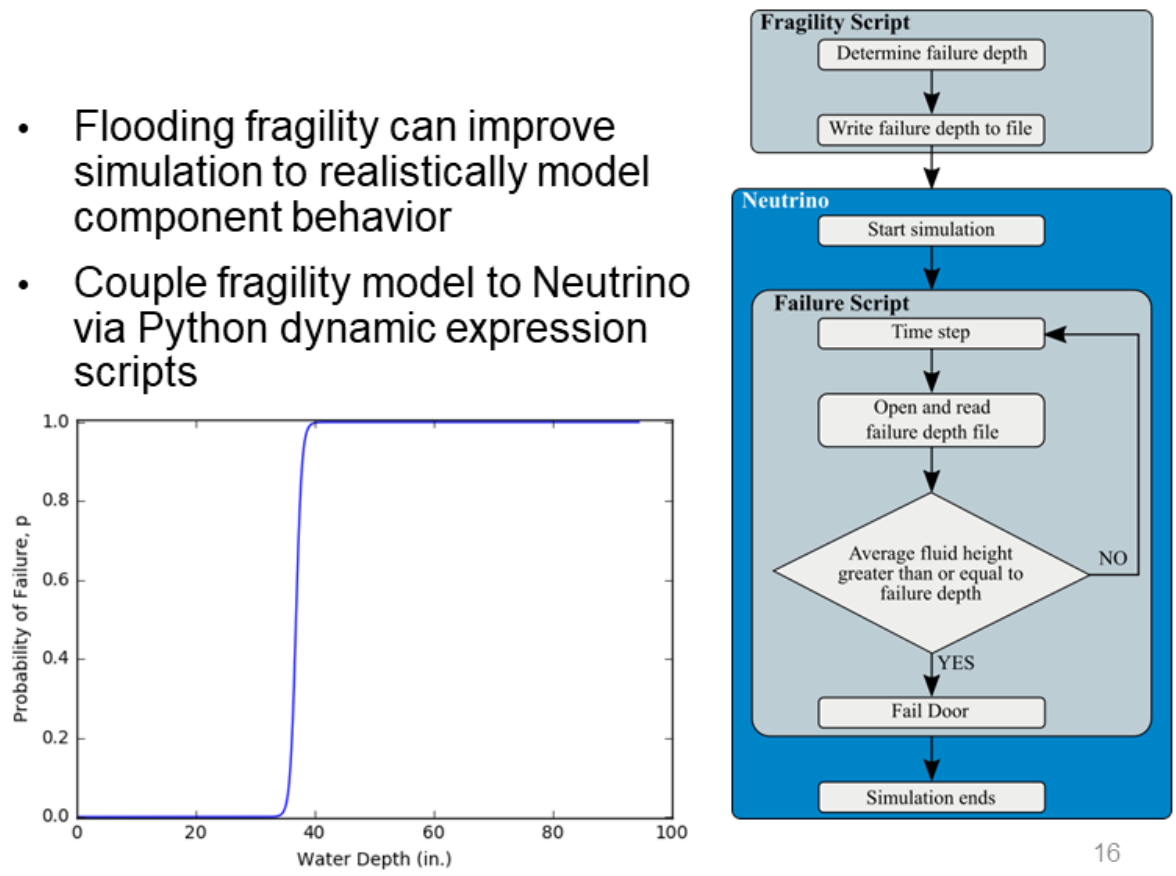


\section{Simulation with Fragility}

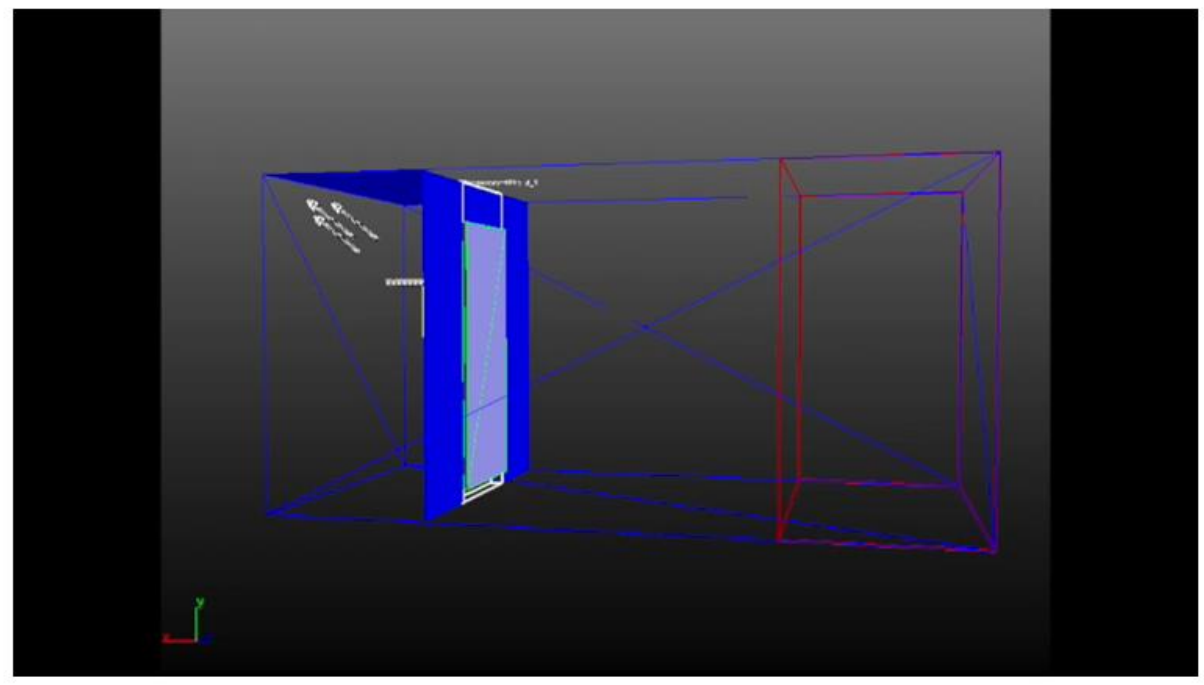

\section{Conclusion}

- Significant progress has been made in all three pathways

- Walk-then-run approach for experiment activities

- Detailed research on SPH validation and particle spacing selection

- Detailed research on fragility model development

- Coupling of fragility models and flooding simulation 


\section{References}

\section{PUBLICATIONS}

- E. D. Ryan, C. L. Pope, Coupling of the Smoothed Particle Hydrodynamic Code Neutrino and the Risk Analysis Virtual Environment for Particle Spacing Optimization, Nuclear Technology, DOI: 10.1020/00295450.2019.1704576.

- A. Wells, E. Ryan, B. Savage, A. Tahhan, S. Suresh, C. Muchmore, C. L. Smith, and C. L. Pope, "Non-watertight Door Performance Experiments and Analysis Under Flooding Scenarios," Results in Engineering, 3 (2019)

- E. D. Ryan, B. M. Savage, C. L. Smith, C. L. Pope, "Comparison of Free Surface Flow Measurements and Smoothed Particle Hydrodynamic Simulation for Potential Nuclear Power Plant Flooding Simulation," Annals of Nuclear Energy 126 (2019).

- A. Tahhan C. Muchmore, L. Nichols A. Wells, G. Roberts, E. Ryan, S. Suresh, B. Bhandari, C. L. Pope, "Development of Experimental and Computational Procedures for Nuclear Power Plant Components Under Flooding Conditions, Proceedings of the $201725^{\text {th }}$ International Conference on Nuclear Engineering (2017).

\section{References}

\section{TECHNICAL REPORTS}

- Nuclear Power Plant Component Flooding Fragility Research, C. L. Pope, B. Savage, S. Jash. B. Johnson C. Muchmore, L. Nichols E. Ryan S Suresh A. Tahhan, R. Tuladhar, A. Wells, C. L. Smith, INL/EXT-18-45247, Idaho National Laboratory, Research Report (2018).

- Nuclear Power Plant Mechanical Component Flooding Fragility Experiments FY2017 Report C. L. Pope., B. Savage, B. Johnson, C. Muchmore, L. Nichols, G. 17-43439, Idaho National Laboratory, Research Report (2017).

- Nuclear Power Plant Mechanical Component Flooding Fragility Experiments Status C. L. Pope, B. Savage, B. Johnson, C. Muchmore, L. Nichols, G. Roberts E. Ryan, S. Suresh, A. Tahhan, R. Tuladhar, A. Wells, C. Smith, INL/EXT-17-42728, Idaho National Laboratory, Research Report (2017).

- Flooding Fragility Experiments and Prediction, C. Smith. B. Bhandari, C. Muchmore, A. Tahhan, A. Wells, L. Nichols, C. L. Pope, INL/EXT-16-39963, Idaho National Laboratory, Research Report (2016)

- Status of the Flooding Fragility Testing Development, C. L. Pope, B. Savage, A. Sorensen, B. Bhandari D. A. Kamerman, A. Tahhan, C. Muchmore, G. Roberts, E. Ryan, S. Suresh, A. Wells, C. Smith, INL/EXT-16-39115, Idaho National Laboratory Research Report (2016)

- Progress on the Industry Application External Hazard Analyses Early

Demonstration, C. L. Smith, S. Prescott, J. Coleman, E. Ryan, B. Bhandari, S Sludern, C L. Pope, R. Sampath, INL/EXT-15-36749, Idaho National Laboratory Research Report (2015).

- Industry Application External Hazard Analyses Problem Statement, R. H. Szilard J. Coleman, C. L. Smith, S. Prescott, A. Kammerer, R. Youngblood, C. L. Pope, 


\section{References}

\section{PHD STUDENTS}

- $\quad$ Alison Wells, PhD, Assessing Nuclear Power Plant Component Fragility in Flooding Events using Bayesian Regression Modeling with Explanatory Variables (defense scheduled for April 3, 2020)

- Emerald Ryan, PhD, Determination, Development, and Validation of a Fluid Height Analysis Method and Particle Spacing Protocol for the Smoothed Particle Hydrodynamic Code Neutrino (2019)

\section{MS STUDENTS}

- $\quad$ Cody Muchmore, MS, Categorization and Evaluation of Spray Patterns from Pipe Leaks, (2018)

- Antonio Tahhan, MS, Performance Improvements to the Portal Evaluation Tank, Characterization Analysis of Nuclear Power Plant Component Flooding Tests (2018)

- Soumadipta Jash MS Instrumentation for Measuring Velocity of Wave Produced by Wave Impact Simulation Device for the Idaho State University Component Flooding Evaluation Laboratory (2018)

- Sneha Suresh, MS, Development of an Interior Component Flooding Fragility Model and Design of Component Evaluation Flooding Laboratory Safety Circuit (2017)

- Emerald Ryan, MS, Construction of a Smoothed Particle Hydrodynamic Model for Flow Over an Ogee Spillway Comparison to Determine Viability in Modeling Flooding Scenarios (2016)

- Bishwo Bhandarai, MS, Full Scale Door Testing Under Flooding Conditions to Develop Testing Protocol (2016)

- David Kamerman, MS, The Use of Flooding Fragility Curves in Nuclear Power Plant Risk Analysis (2016)

\subsubsection{Questions and Answers}

Question: Which testing protocol did you use?

Answer: We used a testing protocol developed at ISU. We also compared this protocol to existing testing protocols for pressure vessels to ensure compliance. 


\subsection{Open Discussions}

Question: Is it possible that an extreme condition could occur with multiple concurrent hazards? Can tests for such conditions be performed?

Answer: Conditions with multiple concurrent hazards, either correlated or uncorrelated, are possible. The Fukushima nuclear accident involving an earthquake and a tsunami is an example. Although not addressed in the scope of the NRC FBTS project, the multi-hazard topic has been explored by groups around the world. We are not sure if there is any experimental or testing effort, but we have noted relevant efforts on modeling and simulation for seismically-induced fires and floods, for instance, as investigated by Brookhaven National Laboratory for NRC [3] and as addressed in ASME/ANS RA-S Case 1, "Case for ASME/ANS RA-Sb-2013 Standard for Level 1/Large Early Release Frequency Probabilistic Risk Assessment for Nuclear Power Plant Applications” [4].

Question: (To Prof. Chad Pope) In your research, it looks like empirical data were used to inform simulation. Did you use any mechanistic models?

Answer: We used both empirical and mechanistic models in our flooding simulation. In our Neutrino simulation model, fluid height is compared to failure depth to determine if door failure occurs. Failure depth is sampled from fragility curves, which are empirical models as they are developed based on data obtained from multiple flooding tests. Fluid height is simulated using a smoothed-particle hydrodynamics method, which is a mechanistic method providing numerical solutions for equations of fluid dynamics.

Question: How important is it to measure leak rate?

Answer: It would be ideal to develop component fragility curves as a function of leak rate. But one challenge is the difficulty in measuring leak rate during flood barrier tests. Leak rate might be precisely measured in most exsitu facilities, but it could be a challenging task for in-situ tests. Another challenge is lack of interface between underlying physics and PRA models. Current PRA models usually adopt a crude scheme to categorize component states, i.e., success and failure. It is still unclear how to evaluate the risk significance of a physical factor such as leak rate or to translate component states to values of physical factors. 


\section{WORKSHOP SUMMARY}

The NRC FBTS workshop was held on March 12, 2020 and attended by members of the public, NRC technical staff, management, and contractors, and staff from INL, ISU, and other agencies. An overview of FBTS research as well as the preliminary research results from the project were presented. Industry stakeholders and technical experts provided valuable inputs and insights on flood barrier testing strategies. The discussions from the workshop have led several follow-up actions for the FBTS research.

- On the codes and standards that could be used for nuclear plant flood barrier testing, participants indicated that the Approval Standard for Flood Mitigation Equipment (FM 2510), developed by FM Approvals, could be referred by the NRC research. INL staff agreed to review FM 2510 and include the result into the project report.

- The FM Approval representative mentioned that the USACE - Engineer Research and Development Center (ERDC) in Vicksburg, Mississippi could conduct water testing of flood barriers for opening barrier and perimeter barrier applications. The NRC/INL project team planned to contact the ERDC Mississippi facility after the workshop to discuss the potential nuclear plant flood barrier testing application in the facility.

- For the potential harvesting in decommissioning plants, although decommissioning companies such as Holtec have been contacted and invited to attend the workshop, there were no responses from them to participate. Future efforts will be continued to engage the decommissioning companies on their interest in potential harvesting.

- The INL presentation on plant-specific flood barrier types and performances was interested and widely discussed by the workshop participants. Since the performance results in the presentation were based only on one plant walkdown report, the NRC/INL project team would discuss whether more plant walkdown reports should be reviewed in order to expand/validate the flood barrier performance results with more plant data.

\section{REFERENCES}

[1] Nuclear Energy Institute, "Guidelines for Performing Verification Walkdowns of Plant Flood Protection Features (NEI 12-07, Revision 0-A)," 2012.

[2] FM Approvals, "Approval Standard for Flood Mitigation Equipment (Class Number 2510)," 2019.

[3] G. Martinez-Guridi and J. Lehner, "Draft Progress Report on Scoping Study for a PRA Method for Seismically Induced Fires and Floods," 2015.

[4] American Society of Mechanical Engineers/American Nuclear Society, "Case for ASME/ANS RA-Sb-2013 Standard for Level1/Large Early Release Frequency Probabilistic Risk Assessment for Nuclear Power Plant Applications (ASME/ANS RA-S CASE 1)," 2017. 